\title{
Modelling convective processes during the suppressed phase of a Madden-Julian oscillation: Comparing single-column models with cloud-resolving models
}

\author{
S. J. Woolnough, ${ }^{a}$ P. N. Blossey, ${ }^{b *}$ K.-M. Xu, ${ }^{c}$ P. Bechtold, ${ }^{d}$ J.-P. Chaboureau, ${ }^{e}$ T. Hosomi, ${ }^{f}$ \\ S. F. Iacobellis, ${ }^{\mathrm{g}}$ Y. Luo, ${ }^{\mathrm{h}}$ J. C. Petch, ${ }^{\mathrm{i}}$ R. Y. Wong ${ }^{\mathrm{i}}$ and $\mathrm{S}$. Xie ${ }^{\mathrm{j}}$ \\ ${ }^{\mathrm{a}}$ Walker Institute, University of Reading, Reading, UK \\ ${ }^{\mathrm{b}}$ University of Washington, Seattle, USA \\ ${ }^{\mathrm{c}}$ NASA Langley Research Center, USA \\ ${ }^{\mathrm{d}}$ European Centre for Medium Range Weather Forecasts, Reading, UK \\ ${ }^{\mathrm{e}}$ Laboratorie d'Aerologie, Universite of Toulouse and CNRS, France \\ fJapan Meteorological Agency, Japan \\ ${ }^{\mathrm{g}}$ Scripps Institution of Oceanography, University of California, San Diego, USA \\ ${ }^{\mathrm{h}}$ State Key Laboratory of Severe Weather, Chinese Academy of Meteorological Sciences, China \\ ${ }^{\mathrm{i}}$ Met Office, Exeter, UK \\ ${ }^{\mathrm{j}}$ Lawrence Livermore National Laboratory, USA
}

\begin{abstract}
${ }^{\star}$ Correspondence to: P. N. Blossey, University of Washington, Atmospheric Sciences, Box 351640, Seattle, WA 98195-1640, USA. E-mail: pblossey@u.washington.edu
\end{abstract}

The role of convective processes in moistening the atmosphere during suppressed periods of the suppressed phase of a Madden-Julian oscillation is investigated in cloud-resolving model (CRM) simulations, and the impact of moistening on the subsequent evolution of convection is assessed as part of a Global Energy and Water Cycle Experiment Cloud System Study (GCSS) intercomparison project. The ability of single-column model (SCM) versions of a number of state-of-the-art climate and numerical weather prediction models to capture these convective processes is also evaluated. During the suppressed periods, the CRMs are found to simulate a maximum moistening around $3 \mathrm{~km}$, which is associated with a predominance of shallow convection. All SCMs produce adequate amounts of shallow convection during the suppressed periods, comparable to that seen in CRMs, but the relatively drier SCMs have higher precipitation rates than the relatively wetter SCMs and CRMs. The relatively drier SCMs dry, rather than moisten, the lower troposphere below the melting level. During the transition periods, convective processes act to moisten the atmosphere above the level at which mean advection changes from moistening to drying, despite an overall drying effect for the column. The SCMs capture some essence of this moistening at upper levels. A gradual transition from shallow to deep convection is simulated by the CRMs and the wetter SCMs during the transition periods, but the onset of deep convection is delayed in the drier SCMs. This results in lower precipitation rates for these SCMs during the active periods, although much better agreement exists between the models at this time.

Key Words: GCSS; tropical convection; model intercomparison; cloud-resolving modelling 


\section{Introduction}

This article describes results from a model intercomparison performed as part of a case study (Petch et al., 2007; Willett et al., 2008) of the Precipitating Convective Cloud Systems Working Group (PCCSWG) of the Global Energy and Water Cycle Experiment (GEWEX) Cloud System Study (GCSS). In this study, simulations are carried out using cloud-resolving models (CRMs), which explicitly resolve cloud-scale processes, and single-column model (SCM) versions of numerical weather prediction (NWP)/global climate models (GCMs), which parametrize all cloud processes on scales smaller than that of a GCM grid cell $(\sim 100 \mathrm{~km})$. Previous model intercomparison studies of deep convective cloud systems using CRMs and SCMs were based upon convectively active periods of field experiments that took place over oceans (Bechtold et al., 2000; Redelsperger et al, 2000) and land (Ghan et al., 2000; Xie et al., 2002; Xu et al., 2002; Guichard et al., 2004; Grabowski et al., 2006). In order to understand the deficiencies in the representations of convective processes in GCMs and, in particular, their ability to simulate tropical variability, the present case study includes both suppressed and active periods of tropical deep convection, as well as the transitions from suppressed to active periods during the suppressed phase of the Madden-Julian oscillation (MJO), which has a period of 40-50 days (Madden and Julian, 1972). This case study takes advantage of the high-quality dataset from the Tropical Ocean and Global Atmosphere (TOGA) Coupled Ocean-Atmosphere Response Experiment (COARE; Webster and Lukas, 1992) intensive observation period (IOP), during which multiple MJOs were observed.

While it is well known that convective and large-scale processes are tightly coupled in the Tropics (Emanuel et al., 1994), the primary role of convective processes during the suppressed phase of the MJO is to moisten the atmospheric column. Lin and Johnson (1996) identified periods of significant moistening by both shallow cumulus and cumulus congestus in observations during TOGA-COARE. Johnson et al. (1999) further highlighted the prevalence of these cloud types in the TOGA-COARE period. Johnson and Lin (1997) diagnosed large moistening effects of shallow, non-precipitating cumulus clouds located in the lowest $2-3 \mathrm{~km}$ region of the atmosphere. After the deepening of the moist layer by shallow convection, deep convective episodes usually followed the suppressed periods. Unlike the active phase of the MJO, these episodic deep convective events could last for a day or slightly longer. During the active phase of the MJO, strong winds along with high humidity throughout the troposphere support the development of deep convective cloud systems that can persist for several days. Capturing the differences in these convective processes between the active and suppressed phases of the MJO-in particular, their vertical heating profiles-is key in order for GCMs to simulate tropical variability, in which the MJO plays a major role alongside other convectively coupled equatorial waves (Wheeler and Kiladis, 1999).

Most GCMs have various degrees of difficulty in simulating MJO events, although some of them can produce MJO-like phenomena (Lin et al., 2006). The MJO variances are less than half that observed in 12 of 14 coupled ocean-atmosphere GCMs evaluated by Lin et al. (2006). Even when an MJO signal is produced, the amplitude and phase speed of the phenomena do not match observations simultaneously. For example, the Community Atmospheric Model version 3 (CAM3; Collins et al., 2006) shows very little MJO activity in an Atmospheric Model Intercomparison Project (AMIP) run with prescribed seasurface temperature (SST) (Khairoutdinov et al., 2008). A modified convective parametrization in CAM3, however, enhanced shallow convection during the transition phase of the MJO, and the simulated MJO was stronger but had a shorter period (Zhang and $\mathrm{Mu}, 2005$ ). The relatively short period is related to the lack of persistence of parametrized convection in CAM3, which has difficulty reproducing the low-frequency modes of tropical variability. The European Centre for Medium-Range Weather Forecasts (ECMWF) Integrated Forecast System (IFS) could not reproduce the suppressed phase of the MJO in biweekly to monthly forecasts-instead producing a permanent activelike phase-before the recent modifications to its convective parametrization. These modifications (Bechtold et al., 2008), a reformulation of the entrainment rate that incorporates the effect of environmental relative humidity and a newly variable relaxation time-scale for convective adjustment, allow the model to maintain the amplitude of the MJO and increase tropical variability in biweekly to monthly forecasts. The UK Met Office model (HadGAM3) had a loss of MJO amplitude with forecast range, although both the activity and interannual variability were increased after its mass-flux-based convective parametrization was modified with adaptive entrainment. The eastward propagation of the MJO was still slower than the observed one, however (Ringer et al., 2006).

The same difficulties are greatly reduced with a new climate modelling approach called the 'multi-scale modelling framework' (MMF), in which a two-dimensional (2D) CRM is embedded in each grid cell of the parent GCM and replaces all of the GCM's cloud and convective parametrizations (Randall et al., 2003). Khairoutdinov et al. (2008) found reasonably realistic MJO and higher frequency tropical variability using this framework. Strong MJO variability was also produced using a similar approach in work by Grabowski (2003), who attributed this to a greater sensitivity of convection to the moisture profiles than in conventional parametrizations and to the role of moistening of the atmospheric profiles by shallow convection during the transition from suppressed to active convection. A global cloud-resolving model can maintain MJO characteristics well for a 30 day integration (Masunaga et al., 2008). These results suggest that explicitly simulated convection is more realistic than convection parametrized in GCMs during the suppressed phase of an MJO. The inability of convective parametrizations to produce realistic heating and moistening profiles (resulting, for example, from a lack of shallow convection and cumulus congestus) during the suppressed phase of an MJO is blamed for these difficulties in simulating the MJO variability. Recent efforts have been put into refining entrainment rate formulations in convective parametrizations (Martin et al., 2006; Bechtold et al., 2008; Boyle et al., 2008) based upon the findings presented in Derbyshire et al. (2004).

The results presented in this article represent the major component of a wider case study including CRMs, SCMs and NWP/GCMs. An overview of the case study, the rationales for using CRMs to evaluate SCMs, and the philosophy behind the GCSS intercomparison studies are outlined in 
Petch et al. (2007). The results from the GCM component of this case study are presented in Willett et al. (2008). Three of the six SCMs participating in the present study are also the participants in the GCM study of Willett et al. (2008). The objectives of the present study are twofold. One is to examine the role of convective processes in moistening the atmosphere during suppressed periods of the suppressed phase of an MJO and assess the impact of moistening on the subsequent evolution of the convection in CRM simulations. The other is to evaluate the ability of SCMs to simulate these convective processes against CRMs, with identical large-scale forcing imposed on both sets of models. Since the SCMs experience identical forcings to the CRMs, it is expected that the disparity among the SCMs is smaller than that among the NWP/GCM forecasts that are initialized from reanalysis data as presented in Willett et al. (2008).

Specific questions to be addressed in the present study are as follows. Firstly, what are the dominant convective processes simulated by CRMs during the suppressed periods, and are they reproduced by SCMs? To address this question, the presence of shallow convection in both CRMs and SCMs will be examined, along with the diabatic heating and moistening profiles. Secondly, what physical processes dominate the transition from shallow to deep convection in the lower and upper troposphere, respectively? Does the onset of deep convection occur at the same time in the SCMs and CRMs? Finally, is the intensity of convection during the active periods impacted by its delayed onset in some SCMs? Detailed budget analyses including mass, heat and moisture budgets and time series of convective characteristics will be presented to address all of these questions. Section 2 briefly summarizes the experimental design, which is identical to that detailed in Petch et al. (2007). Section 3 describes the characteristics of participating CRMs and SCMs in some detail, including vertical resolutions for both CRMs and SCMs and horizontal resolutions for CRMs. Results of the intercomparison are presented in section 4 . Section 5 summarizes the main findings of this study and presents the outlook for further advancing the goals of this study.

\section{Experimental design}

Three experimental periods during the TOGA-COARE IOP were chosen to investigate the representation of suppressed convection and the subsequent transition to active convection. (For details of how these periods were selected, see Petch et al. (2007).) Each experiment begins with a few days of active convection to spin up the CRMs. This is followed by periods of suppressed convection and then active convection, with a transition between the suppressed and active periods. For the purpose of the following analysis, it is convenient to define these periods of suppressed and active convection within each experiment to investigate the different convective processes associated with each period While Petch et al. (2007) use the convective activity in their CRM to define the suppressed and active periods, we define the active and suppressed periods by the nature of the largescale forcing applied in this single-column framework. The advantage of this method is that the periods are the same in each model and and do not depend on the response of an individual model to the forcing. The suppressed periods are defined by periods when the large-scale forcing is acting to dry and warm the column, which roughly correspond to periods when the forcing is driven by large-scale descent.
The active periods are defined by periods during which there is substantial cooling and moistening of nearly the entire column by the large-scale forcing. Here, substantial cooling is defined as the cooling that would balance a precipitation rate greater than $8 \mathrm{~mm} \mathrm{day}^{-1}$. This captures the periods in each experiment where cooling extends through most of the depth of the troposphere. As the transitions between the suppressed and active periods are not sharp, the periods have been defined in terms of whole days as a convenience. While the definition of substantial cooling and the choice of the start and end of each period (suppressed, transition and active) are somewhat arbitrary, the results presented here are robust to small changes to these definitions. The first two days of each experiment are considered as a spinup period and the simulated characteristics of convection are mostly ignored. Figure 1 shows the prescribed largescale forcing for each experiment with the suppressed and active periods marked. Note that the forcings contain many spatial and time-scales-some of them much shorter than those associated with the MJO-that are characteristic of the natural variability of convection in this region.

The large-scale forcings used in this study were derived by Ciesielski et al. (2003) to reproduce, approximately, the conditions in the Intensive Flux Array (IFA) during TOGA-COARE. The models are forced by prescribed total large-scale advection (horizontal and vertical, combined) and by sea-surface temperature and pressure. No largescale forcing is applied above $150 \mathrm{hPa}(\sim 15 \mathrm{~km})$ due to uncertainties in the forcings there. The surface fluxes of heat, moisture and momentum are computed interactively. The domain-average winds are relaxed to the observed wind profiles on a two hour time-scale, because the models are unable to predict the domain-average momentum profiles due to the lack of geostrophic pressure gradient force (Grabowski et al., 1996; Xu and Randall, 1996).

The prescription of large-scale forcings in this manner permits the development of large temperature anomalies in the models due to an imbalance between the prescribed large-scale forcing and the modelled surface fluxes and radiative and convective heating. In the tropical atmosphere, large-scale circulations quickly develop to redistribute buoyancy anomalies, resulting in weak horizontal temperature gradients and small variations in temperature (Sobel and Bretherton, 2000). As the largescale forcing is specified in these simulations, this feedback does not exist, and the models are free to generate large temperature variations. These variations can result from errors in the large-scale forcing leading to large enthalpy tendencies in the forcing (Emanuel and Živković-Rothman, 1999; Wu et al., 2000) or errors in the representation of the convective response to the forcing, including radiative effects of convective clouds. In full GCM simulations, the modelled differences in the heating and temperature would lead to differences in the evolution of the large-scale circulation, which would feed back on the subsequent evolution of the convection. The impact of this feedback between the convection and the large-scale circulation is addressed in Willett et al. (2008), in which simulations of this period using the parent GCMs of three of the SCMs (SCAM3, IFS, and UM) used in this study are analysed. These feedbacks can be incorporated into SCMs and CRMs through the use of the weak temperature gradient approximation (Sobel and Bretherton, 2000; Raymond, 2007), in which buoyancy anomalies relative to a prescribed sounding are removed 

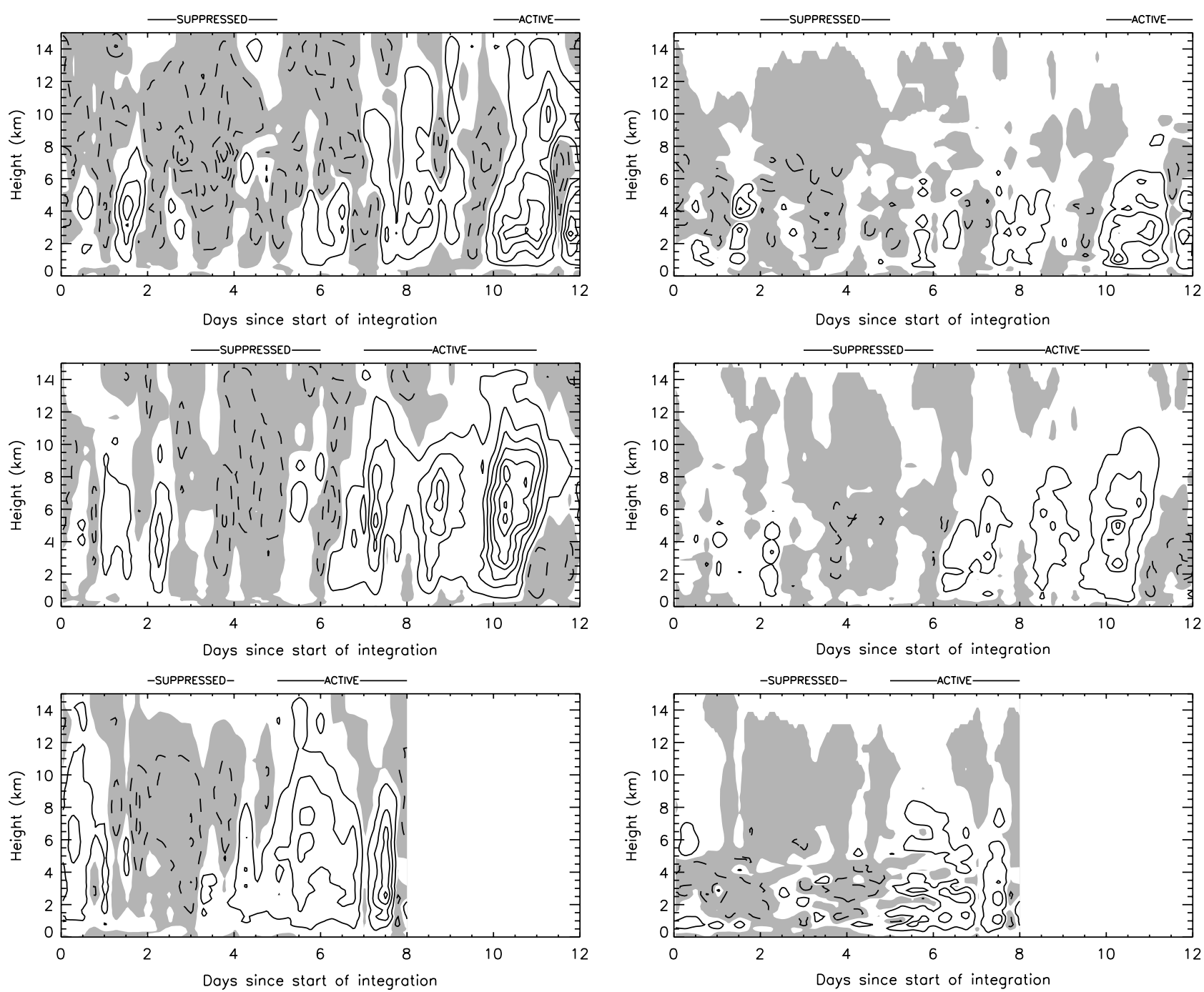

Figure 1. Prescribed large-scale forcing for each experiment. The left-hand column shows the large-scale cooling (K day $\left.{ }^{-1}\right)$ and the right-hand column shows the large-scale moistening $\left(\mathrm{g} \mathrm{kg}^{-1} \mathrm{day}^{-1}\right)$. Cooling and moistening, roughly corresponding to ascent, are shown in solid contours and warming and drying, roughly corresponding to descent, are shaded and shown in dashed contours. The top row is experiment A0 (contour interval 2 beginning at \pm 1 ). The middle row is experiment B0 (countour interval 4 beginning at \pm 2 ) and the bottom row is experiment $\mathrm{C} 0$ (contour interval 4 beginning at \pm 2 ). The suppressed and active periods are marked in each experiment.

by large-scale vertical motion. Such a framework is under consideration for a future GCSS intercomparison study.

Each experimental period in the present study has different features in the large-scale forcing. Experiment A0 (0Z 28 November to 0Z 10 December 1992) has a long gap between the suppressed and active periods with a relatively short and weak active period. A very short gap between the suppressed and active periods distinguishes experiment B0 (0Z 9 January to 0Z 21 January 1993), along with a very strong active period that has maximum cooling rates larger than $30 \mathrm{~K} \mathrm{day}^{-1}$ in the mid-troposphere. Experiment C0 (0Z 21 January to 0Z 29 January 1993) has a shorter suppressed period. The transition between suppressed and active periods during $\mathrm{C} 0$ is marked by a delay of a day in the onset large-scale moistening following the initiation of the large-scale cooling.

\section{Participating models}

Three CRMs and six SCMs participated in this study; they are summarized in Tables I and II. With one exception, the CRM simulations presented here are two-dimensional
(2D). The effect of dimensionality (2D versus 3D) on CRM simulations has been widely examined for individual models (Grabowski et al., 1998; Donner et al., 1999) and model intercomparisons (Xu et al., 2002; Petch et al., 2008). While there are intermodel differences among 2D CRMs that are comparable to those between $2 \mathrm{D}$ and $3 \mathrm{D}$ versions of the same model, previous studies and this study suggest that 2D models are useful for SCM evaluations, due to smaller spreads among CRMs (Xu et al. 2002; Xie et al. 2002). A brief description of each of the models (CRMs and SCMs) used in this study follows.

\subsection{Cloud-resolving models (CRMs)}

The Met Office Large Eddy Model (MOLEM) is described in Shutts and Gray (1994) and Petch and Gray (2001). It includes a five-category prognostic microphysical scheme (Swann, 1998; Brown and Heymsfield, 2001) which has been run with prognostic variables for both mass and number concentration for ice. The subgrid turbulence scheme is based on the Smagorinsky-Lilly model (see Brown et al. (1994) for further details). A third-order advection scheme 
Table I. Summary of CRMs used in this intercomparison.

\begin{tabular}{lllll}
\hline Model & Model full name & Version & Modeller & Reference(s) \\
\hline $\begin{array}{l}\text { SAM } \\
\text { UCLA/LaRC }\end{array}$ & $\begin{array}{l}\text { System for Atmospheric Modelling } \\
\text { University of California-Los Ange- } \\
\text { les/NASA Langley Research Centre } \\
\text { CRM }\end{array}$ & 6.3 & $\begin{array}{l}\text { Blossey } \\
\text { Luo, Xu }\end{array}$ & $\begin{array}{l}\text { Khairoutdinov and Randall (2003) } \\
\text { Krueger (1988); Xu and Krueger } \\
\text { MOLEM }\end{array}$ \\
Met Office Large Eddy Model & 2.3 & Petch & $\begin{array}{l}\text { Shutts and Gray (1994); Petch and } \\
\text { Gray (2001) }\end{array}$ \\
\hline
\end{tabular}

Table II. Summary of SCMs used in this intercomparison. NZ refers to the number of levels below $20 \mathrm{~km}$.

\begin{tabular}{|c|c|c|c|c|c|}
\hline Model & Model full name & Version & NZ & Modeller & Reference(s) \\
\hline SCAM3 & $\begin{array}{l}\text { NCAR Community Atmosphere } \\
\text { Model }\end{array}$ & 3.0 & 20 & Xie & Collins et al. (2006) \\
\hline UM & Met Office Unified Model & 6.0 & 31 & Wong & Martin et al. (2006) \\
\hline JMA & $\begin{array}{l}\text { Japan Meteorological Agency } \\
\text { Global Spectral Model }\end{array}$ & & 29 & Hosomi & JMA (2006) \\
\hline Scripps & Scripps SCM & & 50 & Iacobellis & $\begin{array}{l}\text { Iacobellis and Somerville (2000); } \\
\text { Iacobellis et al. (2003) }\end{array}$ \\
\hline Meso-NH & Meso-NH & 4.5 & 42 & Chaboureau & Lafore et al. (1998) \\
\hline ECMWF IFS & $\begin{array}{l}\text { European Centre for Medium- } \\
\text { Range Weather Forecasts Inte- } \\
\text { grated Forecasting System }\end{array}$ & $29 \mathrm{r} 1$ & 38 & Bechtold & ECMWF (2008) \\
\hline
\end{tabular}

is used for scalars. The radiation scheme included in the model is described in Edwards and Slingo (1996), and its configuration in the CRM is given by Petch and Gray (2001). The domain size is $375 \mathrm{~km} \times 20 \mathrm{~km}$ with $\Delta x=500 \mathrm{~m}$ and a stretched grid in the vertical with $\Delta z=250 \mathrm{~m}$ between 2.5 and $14 \mathrm{~km}$.

The dynamics of the UCLA/LaRC CRM are based on the anelastic system in two dimensions (Krueger, 1988; $\mathrm{Xu}$ and Krueger, 1991). The physical parametrizations in the model consist of a third-moment turbulence closure (Krueger, 1988), a bulk three-phase microphysics (Lin et al., 1983; Lord et al., 1984; Krueger et al., 1995), and an interactive solar and infrared radiative transfer scheme (Fu and Liou, 1993; Fu 1996; Fu et al., 1998). Turbulent surface fluxes are diagnosed using flux-profile relationships based on Monin-Obukhov surface-layer similarity theory (Businger et al., 1971). The domain size is $256 \mathrm{~km} \times 20 \mathrm{~km}$ with $\Delta x=500 \mathrm{~m}$ and a stretched grid in the vertical with $\Delta z=500 \mathrm{~m}$ above $4.5 \mathrm{~km}$.

The System for Atmospheric Modelling (SAM) is described in detail in Khairoutdinov and Randall (2003). It has prognostic equations for liquid water-ice static energy, total water (vapour, cloud) and precipitating water that are integrated numerically using a positive-definite, monotonic advection scheme. A single moment, bulk microphysics scheme is used, and phases of cloud condensate and precipitate are distinguished by a temperature diagnostic. Here, version 6.3 is used, and it differs from the description in Khairoutdinov and Randall (2003) mainly in the fall speed of cloud ice, which depends on ice water content following Heymsfield (2003). Radiative heating is calculated using the optional CAM3.0 scheme, and a Smagorinsky-Lilly subgrid parametrization is used. Both $2 \mathrm{D}$ and $3 \mathrm{D}$ simulations have been performed with this model. The domain sizes are
$256 \times 29.9 \mathrm{~km}^{2}(2 \mathrm{D})$ and $64 \times 64 \times 29.9 \mathrm{~km}^{3}$ (3D) with $\Delta x=500 \mathrm{~m}$ and $\Delta z=50-250 \mathrm{~m}$ in the troposphere.

\subsection{Single-column models (SCMs)}

The SCAM3 is the single column version of the National Center for Atmospheric Research (NCAR) CAM version 3, which is based on the physics from version 3.1 (Collins et al., 2006). Its deep convection scheme is based on that of Zhang and McFarlane (1995) with a CAPE closure. The shallow convection scheme is based on Hack (1994). It has the prognostic cloud scheme of Rasch and Kristjansson (1998) and a non-local boundary-layer scheme (Holtslag and Boville, 1993).

The UM SCM is taken from the global forecast version of the Met Office Unified Model that was used operationally during 2005. The model shares its dynamics and physics with the atmospheric component of the Hadley Centre Global Environment Model (HadGEM1; Martin et al., 2006). Its convection scheme is based on the mass-flux scheme of Gregory and Rowntree (1990) but with significant modifications (see Martin et al., 2006, and references therein for details). The cloud scheme is based on Smith (1990) and it has the first-order turbulence closure boundary-layer scheme of Lock et al. (2000).

The Japan Meteorological Agency (JMA) SCM is based on the physics from the JMA Global Spectral Model GSM0502 (Japan Meteorological Agency, 2006). Its convection scheme is an economical version of the Arakawa-Schubert scheme (Arakawa and Schubert, 1974) with convective momentum transport. It has a prognostic cloud scheme similar to that of Smith (1990), and the boundary-layer scheme is the level 2 closure scheme of Mellor and Yamada (1974).

The Scripps SCM contains parametrizations from several modern GCMs. It contains the convection scheme of Zhang 

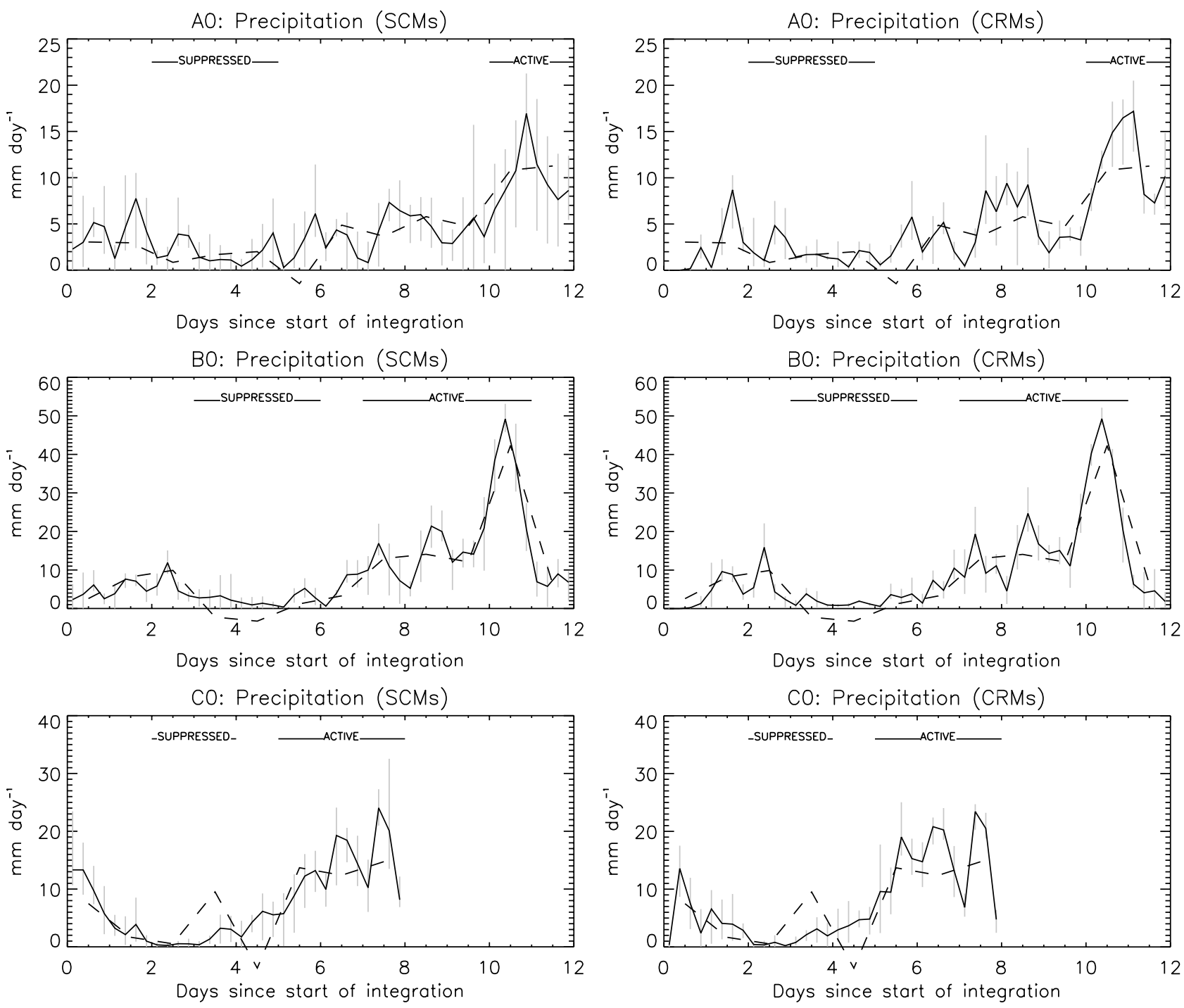

Figure 2. Simulated six-hourly averaged precipitation rates (solid line) for each experiment (mm day ${ }^{-1}$ ) averaged across all SCM integrations (left-hand column) and CRM integrations (right-hand column). The grey shows the range (min-max) of the precipitation rates across the models within each model type. The suppressed and active periods are marked. The dashed line shows the daily-mean, budget-derived estimates of the observed precipitation. Note that these estimates are sometimes negative.

and McFarlane (1995) with CAPE closure, the prognostic cloud scheme of Tiedtke (1993) and the boundary-layer scheme from CAM3 (Holtslag and Boville, 1993; Boville and Bretherton, 2003). The long-wave radiation is parametrized using the Rapid Radiation Transfer Model (RRTM) of Mlawer et al. (1997), and the scheme of Briegleb (1992) is used to compute short-wave radiative fluxes.

The Meso-NH SCM is based on the physics from version 4.5 of the mesoscale Meso-NH model (Lafore et al., 1998). It uses a convection scheme based on that of Bechtold et al. (2001) with a CAPE closure, the prognostic cloud scheme of Pinty and Jabouille (1998) with a modified ice to snow autoconversion parametrization following Chaboureau and Pinty (2006), and the 1.5 order BL scheme of Cuxart et al. (2000).

The ECMWF IFS SCM is taken from cycle $29 \mathrm{r} 1$ of the ECMWF Integrated Forecast System, which was operational during spring/summer 2005. Convection is represented with the aid of a bulk mass-flux scheme that either produces deep, shallow or mid-level convection (Bechtold et al., 2004, and references therein). Cloud condensate produced by convection is a source term to the large-scale cloud scheme that predicts cloud condensate and cloud fraction (Tiedtke, 1993). The radiative fluxes are computed from 16 spectral bands in the long wave and six short-wave bands (Morcrette, 2002).

\section{Results}

This section describes the main results from the case study. The general behaviour of the models during the integrations is described in section 4.1. Sections 4.2-4.4 give a more detailed analysis of the moisture budget and the behaviour of the clouds during the suppressed, active and transition periods respectively.

\subsection{General behaviour of the models}

Figure 2 shows the simulated precipitation averaged over each six-hour period and across the models for each model type (CRM or SCM), along with the range of precipitation across the models within the model type for each integration. A budget-derived estimate of the observed precipitation rates is also shown. Note that the vertical scale differs in the three 

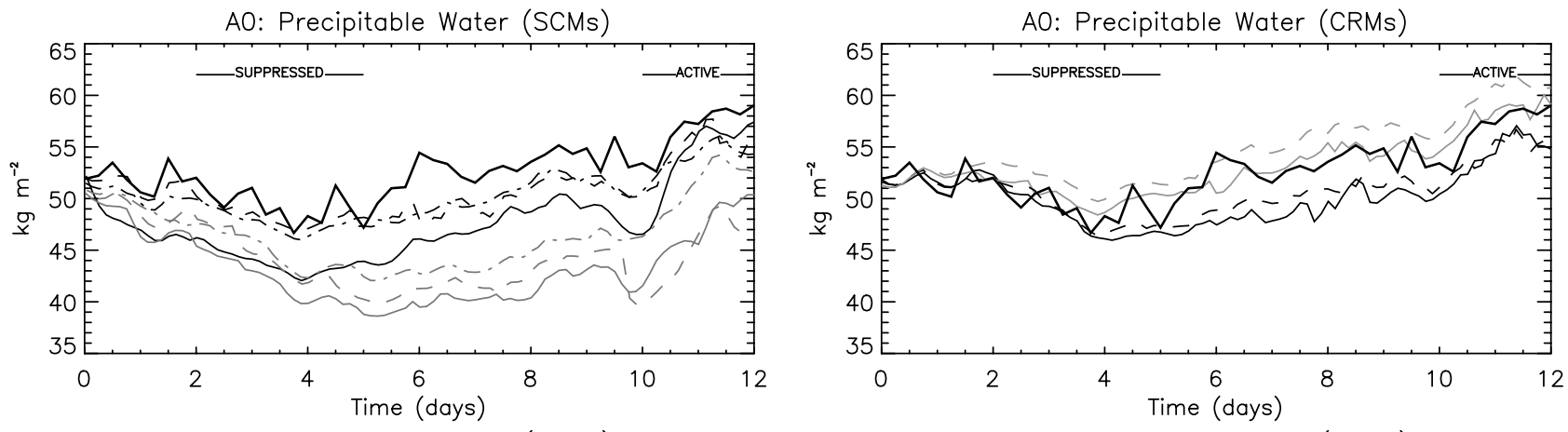

BO: Precipitable Water (SCMs)

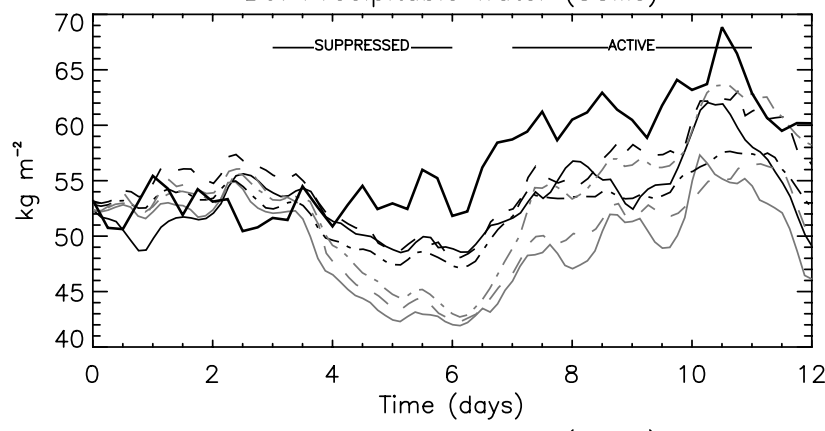

BO: Precipitable Water (CRMs)

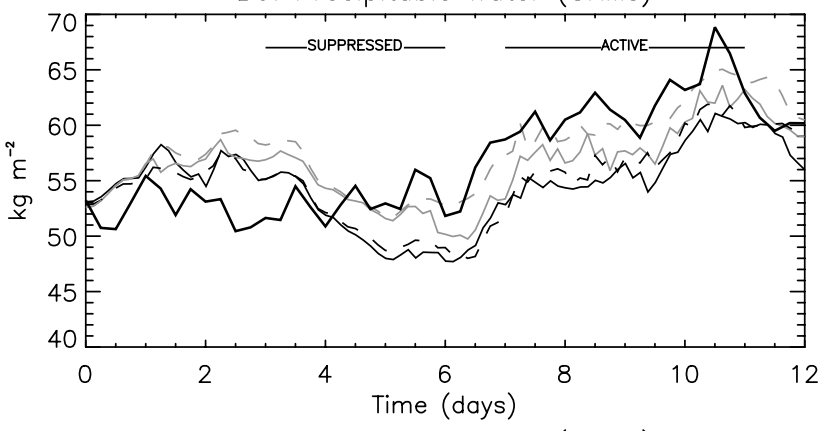

CO: Precipitable Water (CRMs)
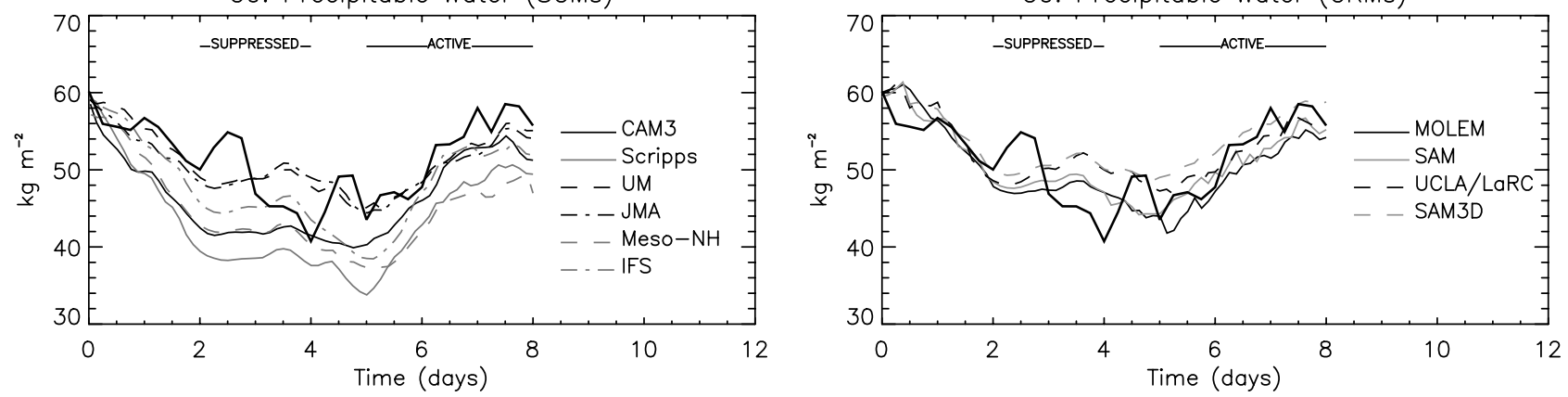

Figure 3. Simulated precipitable water for SCM integrations (left column) and CRM integrations (right column) for experiments A0, B0 and C0. For comparison the observed precipitable water is shown in the thick curve.

experiments because of different maximum precipitation rates. The six-hour average is used because observational data are available at this time interval. As is well known with CRM and SCM simulations, the precipitation rate is strongly constrained by the large-scale forcing on time-scales of more than a day, and this effect can be seen here. The simulated precipitation rates are broadly consistent with the observations and with each other. All the simulations capture the observed suppressed and active periods, and on daily time-scales or longer the differences between the simulated and observed precipitation rates are generally within the error estimates for the observed precipitation rates of Mapes et al. (2003). It is worth noting here that the budget-derived estimates of the observed precipitation are often negative during the suppressed period, and this indicates the potential magnitude of the errors in these estimates and the difficulties in making quantitative comparisons between the models and observations. The transition between the suppressed period and the active period is characterized by a relatively steady increase in precipitation in the models and observations. However, this steady increase in precipitation is associated with a steady increase in the forcing, and it is likely that the main features of this transition in the simulations here are largely determined by the specified large-scale forcing applied in our single-column framework.
The variability in precipitation among individual SCM integrations often exceeds that among individual CRM integrations during the active periods. This is most visible here on a six-hour time-scale during the last three days of experiment A0. However, this also holds on a one-day timescale in all three experiments, as seen in Table IV. Much of this variability is associated with the timing of individual precipitation events in each SCM and is symptomatic of a noisier evolution of precipitation in some SCMs than that found in the CRMs.

Figure 3 shows time series of the precipitable water (PW) for each experiment for all the models and, for comparison, the observations. The cloud-resolving models generally show good agreement, both with each other and with the observations. In addition, the spread among the CRMs is smaller than that among the SCMs, as in previous intercomparisons (Guichard et al., 2004). The evolution of PW in the CRMs during days 3-6 of experiment B0 shows a very different trend to the observed PW during this period. However, at this time the budget-derived rainfall rates in the observations are around $-1.3 \mathrm{~mm}_{\text {day }}{ }^{-1}$, so there are clearly some errors in the derived advective tendencies at that time, which would lead to discrepancies between the model and observations. Despite the lack of agreement between the models and observations at this time and given the known 
errors in observed budgets, the comparison between CRMs and SCMs for this period in conjunction with the other two experiments is still useful. The SCMs are on average drier than the CRMs (comparing the CRM and SCM distributions of precipitable water using a two-sided Mann-Whitney test (Mann and Whitney, 1947) shows significance at the $10 \%$ level for most of the time during each of the three experiments). However, there is much greater variability in the simulated PW between the SCMs, with differences in PW of between $10-15 \mathrm{~kg} \mathrm{~m}^{-2}$ by the end of the A0 and B0 integrations. The characteristics of the SCM simulations of PW show generally consistent behaviour across the three experiments. Two of the models (Scripps and Meso-NH) are generally much drier than the other SCM simulations (and CRM simulations), and two of the SCM simulations (UM and JMA) are generally more moist and comparable to the CRMs.

Much of the drying in the SCM integrations relative to the CRMs occurs during the first two days of the A0 and $\mathrm{C} 0$ integrations. When averaged over the three experiments, the SCMs are $3.8 \mathrm{~kg} \mathrm{~m}^{-2}$ drier after the first 48 hours when averaged over the three integrations, mostly as a result of larger surface precipitation in the SCMs. Results during this period are influenced by the 'spin-up' of the CRMs (the development of precipitating cumulus convection from a cloudless initial state) and by 'spin-down' in the SCMs (which often experience precipitation maxima soon after initialization (Grabowski et al., 2006)), although systematic errors in the representation of convective and precipitation processes could also play some role in these differences.

To eliminate discrepancies associated with this spin-up period, Figure 4 shows the time evolution of the difference in PW for each of the SCMs from that model's own PW at 48 hours, along with the range of the four CRM integrations. The good agreement of the UM and JMA SCMs with the evolution of the CRMs is apparent for each of the experiments. SCAM3 is in good agreement with the CRMs in experiment A0, but is relatively moist compared with the other models in experiment B0. The Scripps and Meso$\mathrm{NH}$ SCMs-and to a lesser extent the IFS SCM-continue to be dry relative to the other SCMs and the CRM mean beyond the spin-up period in experiments $\mathrm{A} 0$ and $\mathrm{B} 0$, predominantly during the suppressed period. There is much better agreement between all the models in the evolution of the PW beyond the spin-up phase in experiment $\mathrm{C} 0$. The differences in the evolution of PW during the suppressed period of experiments $\mathrm{A} 0$ and $\mathrm{B} 0$ are used to divide the SCMs into two groups: WET models (UM, JMA, SCAM3) and DRY models (Scripps, Meso-NH, IFS). The distinction between these two groups is useful in the analysis in sections 4.2-4.4.

Figures 5 and 6 show the changes in temperature and water vapour, respectively, from the initial conditions in each model for experiment A0. While the modelled humidity fields vary more substantially from experiment to experiment, the evolution of the temperature in the observations and in the models during this experiment is generally representative of their behaviour in the other experiments. The observations show very small variations in temperature throughout the period, of the order of $1-2{ }^{\circ} \mathrm{C}$. In contrast, all the models show larger and more coherent temperature variations than the observations. The drying in the models relative to the initial sounding tends to be stronger and/or more persistent than that in the

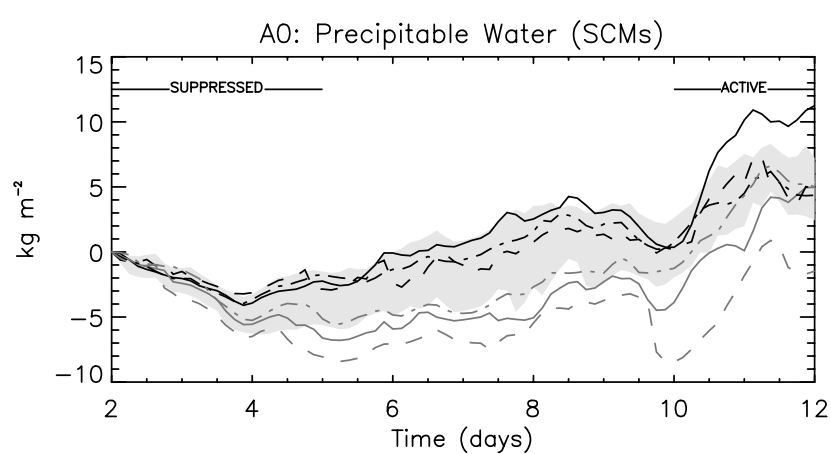

BO: Precipitable Water (SCMs)

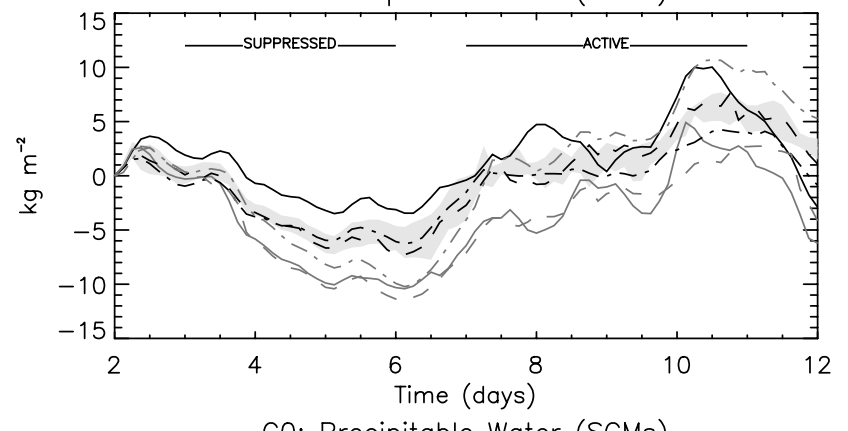

CO: Precipitable Water (SCMs)

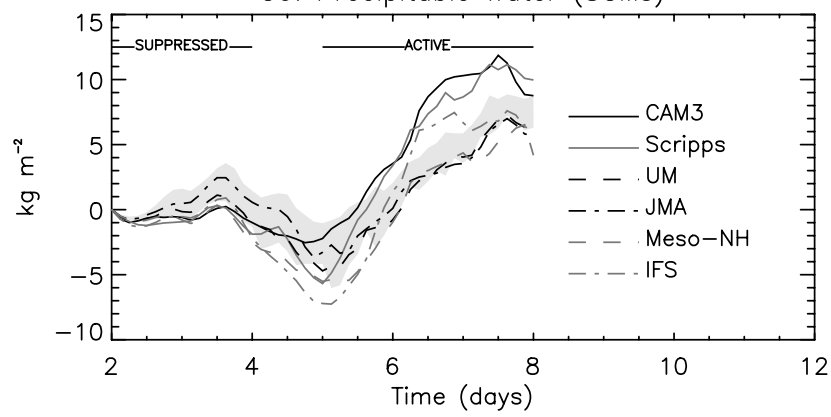

Figure 4. Difference in precipitable water from that at 48 hours for each SCM integration for experiments A0, B0 and C0. The grey shading shows the range across the CRM integrations for each experiment.

observations. The stronger dry layers in some of the models are suggestive of those studied by Mapes and Zuidema (1996). The observations show a peak in moistening near the melting layer, which builds in strength during the transition and active periods of this experiment. All of the models tend to be cool relative to the observations during the active period of the experiment in the upper troposphere.

The CRMs have a similar pattern of evolution and the differences between the CRM simulations are generally small compared with the difference between the CRMs and the observations for the temperature field. The intermodel differences in humidity are similar to those between the models and the observations. While the temperature discrepancies between the CRMs and observations could arise in part from systematic errors in the models, the consistency of three CRMs with formulations that differ substantially suggests that imbalances in the diagnostic dry static energy budget of the large-scale forcings could be responsible in part for the drift. The warming near $15 \mathrm{~km}$ in many of models results from a lack of any large-scale forcing above $150 \mathrm{hPa}(\sim 15 \mathrm{~km})$, which allows the models to warm in response to radiative heating there. The CRMs perform well in simulating the humidity variations during this experiment, with SAM and MOLEM capturing both peaks in moistening during the active period, although they 

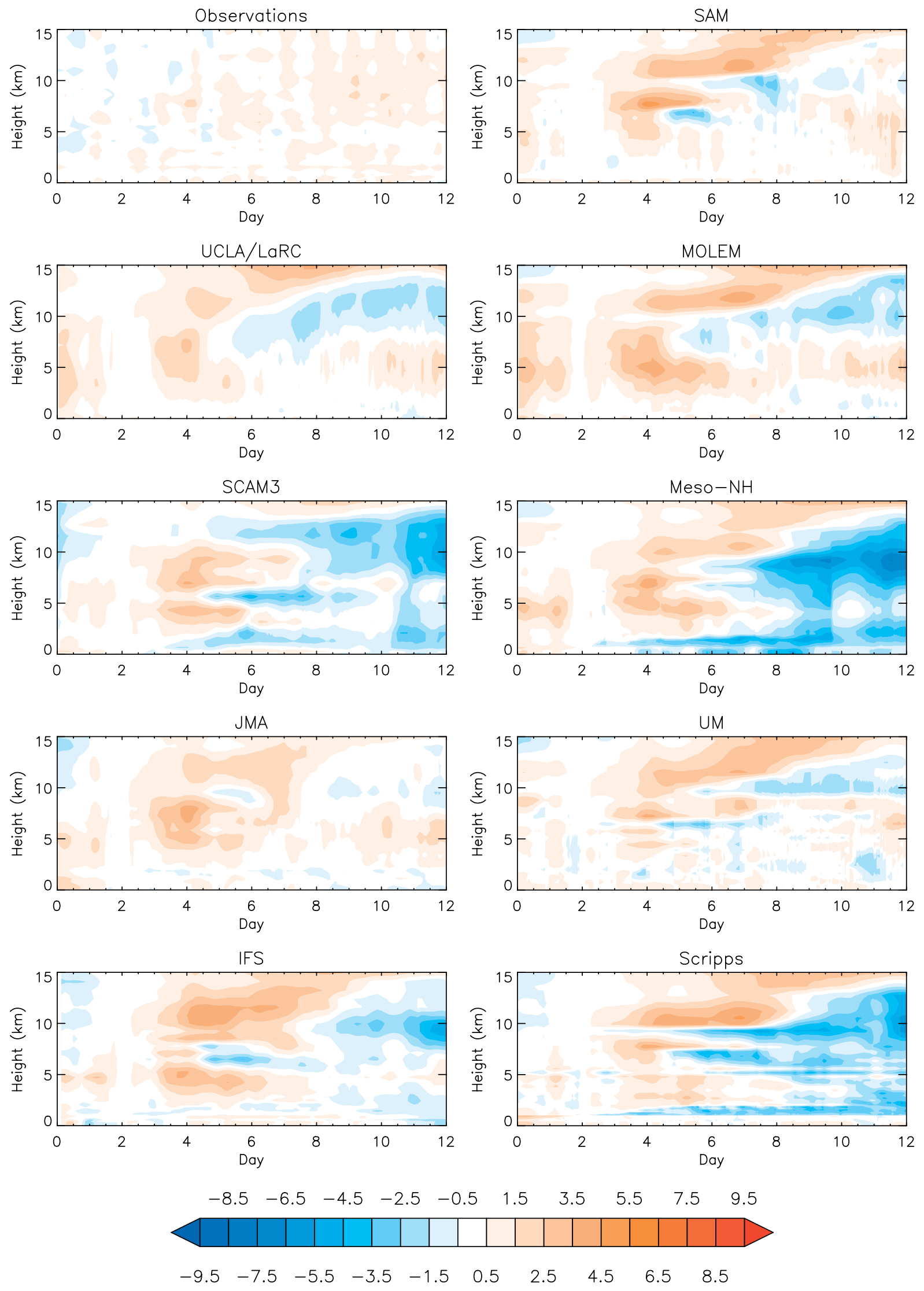

Figure 5. Change in temperature (K) from initial conditions for the observations and each model for experiment A0. 

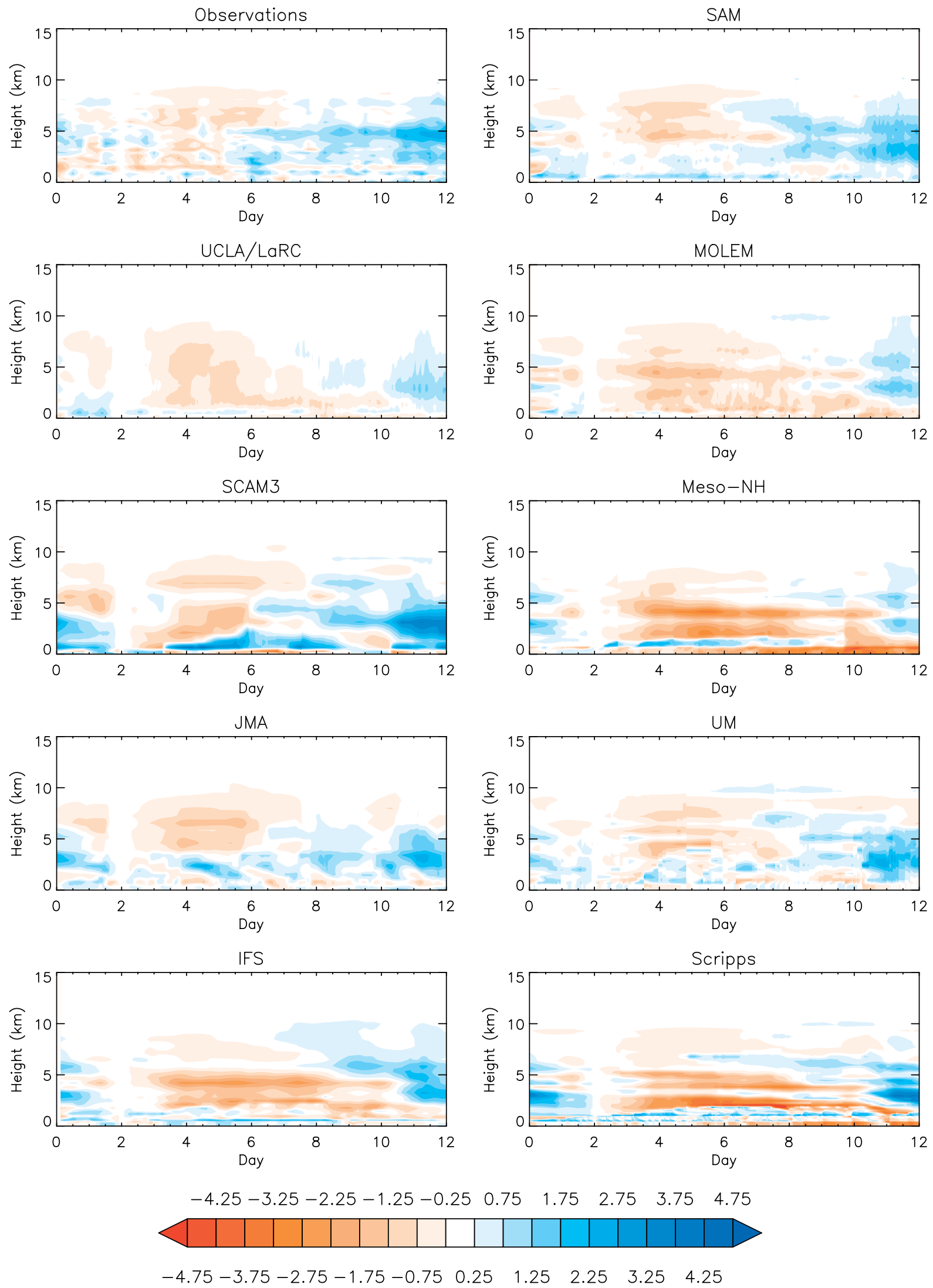

Figure 6. Change in water-vapour mixing ratio $\left(\mathrm{g} \mathrm{kg}^{-1}\right)$ from initial conditions for the observations and each model for experiment A0.

both reverse the relative strength of the peaks. The essence of that moistening is captured by all of the models. Also, MOLEM, and to a lesser extent the UCLA/LaRC CRM, tends to remain dryer than observed through the transition period.
With the exception of SCAM3, the SCMs show a generally similar pattern of temperature anomalies in the upper troposphere to those in the CRMs, with warming in the midtroposphere during the suppressed period and near $15 \mathrm{~km}$ during the transition and active periods and cooling in the 

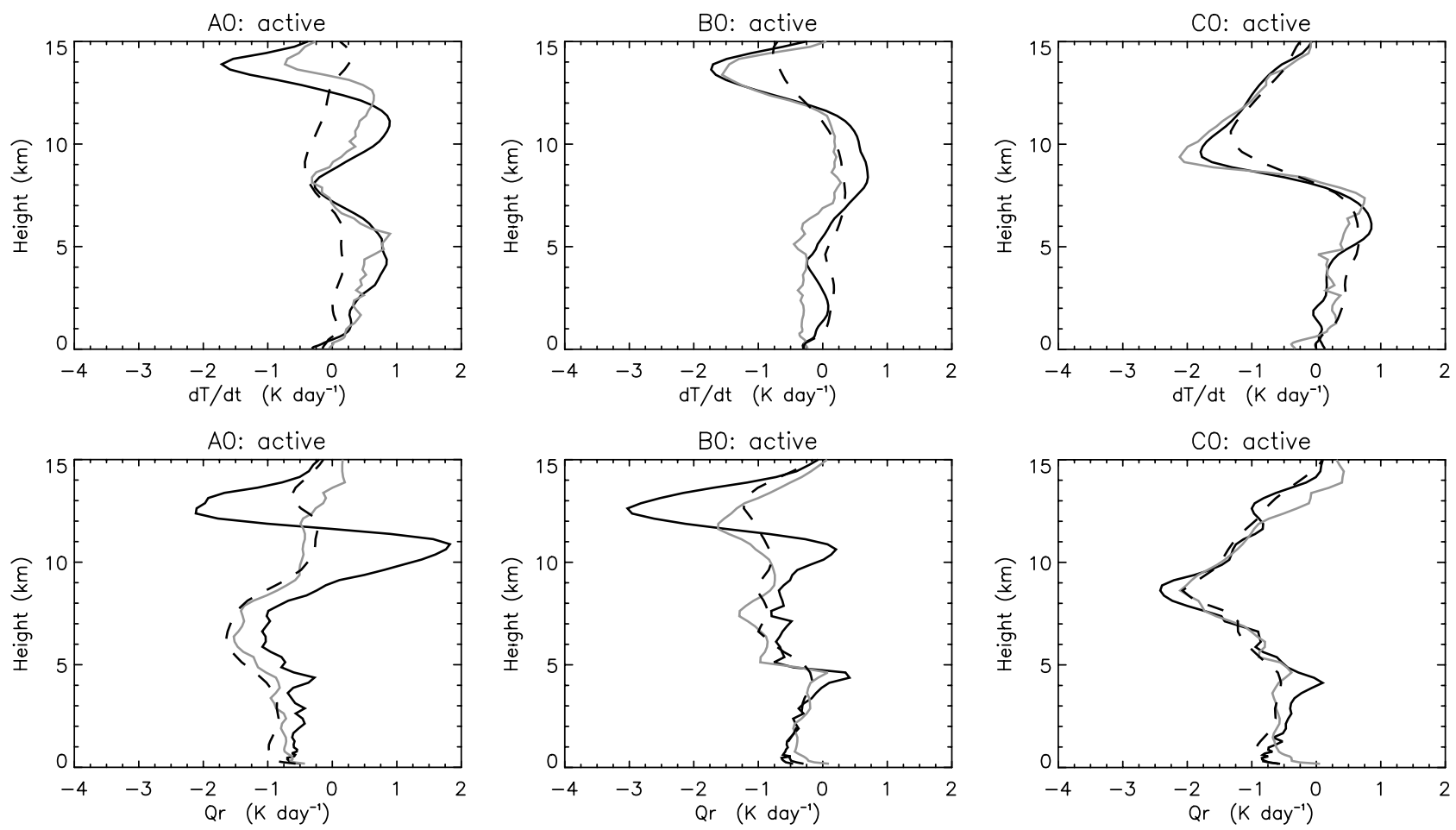

Figure 7. Total temperature tendency-including large-scale forcing and all diabatic and adiabatic processes-during the active period (top row) and contribution of the radiative heating (bottom row) to the total tendency for each experiment in the 2D CRMs (MOLEM: solid black line; UCLA/LaRC: dashed black line; SAM2D: solid grey line).

upper troposphere during the active period. The WET SCMs also have largely similar patterns of moisture anomalies (relative to the initial sounding) to the CRMs. The DRY SCMs, however, show more persistent dry anomalies in the lower troposphere that are removed only with the onset of the active period, although some moistening near and above the melting layer does occur during the transition period (days 5-10). The DRY SCMs, along with SCAM3, are colder than observed in the lower troposphere as well. The larger differences found between the individual SCM integrations, compared with those between the CRM integrations, are in agreement with the studies of Xie et al. (2002) and Xu et al. (2002).

Despite the relatively close agreement in the evolution of the temperature profiles in the CRMs, there are some differences in the processes that lead to these temperature tendencies. Figure 7 shows the total temperature tendencies in the CRMs during the active period of each experiment and the contribution to the total tendency from the radiative heating terms. In experiments A0 and B0, MOLEM shows a significant dipole in radiative heating in the upper troposphere, with strong warming at the base of the highlevel ice clouds and stronger cooling at cloud top, which is not seen in the other CRMs. This difference arises from differing treatments of microphysics and cloud-radiation interactions among the CRMs. A detailed discussion of such differences and their impact on the evolution of the convection is outside of the scope of this article, but will form the focus of a future GCSS Case Study.

The analysis in the subsequent sections will focus on the evolution of the moisture field during the suppressed and active periods in turn, followed by an analysis of the transition between them, with a focus on the impact of the simulated convective moistening on that transition.

\subsection{The suppressed period}

The suppressed periods are defined in these integrations by the presence of large-scale warming and drying of the profile, associated with large-scale descent. Figure 8 shows the apparent moisture source, $-Q_{2}$ (Yanai et al., 1973), in units of $\mathrm{g} \mathrm{kg}^{-1}$ day $^{-1}$ from each of the models in response to this forcing. Note that we have plotted the apparent moisture source- $\mathrm{Q}_{2}$, rather than the apparent moisture sink $\mathrm{Q}_{2}$, so that positive values in these plots correspond to convective moistening, negative values to drying. Table III shows the precipitation $(\mathrm{P})$ and evaporation rates $(\mathrm{E})$ for each model averaged over the suppressed period. The difference, P-E, is equal to the vertical integral of apparent moisture source over the entire atmospheric column.

The CRM integrations all exhibit an excess of evaporation over precipitation during the suppressed period for all the experiments, as seen in Table III. The apparent moisture source has a peak in the lower troposphere at around $2-3 \mathrm{~km}$ (Figure 8), which is similar in some respects to that seen by Johnson and Lin (1997) during an extended light-wind, suppressed period of TOGA-COARE (14 November-5 December 1992) that ends with the suppressed period of experiment $\mathrm{A} 0$. In experiments $\mathrm{A} 0$ and $\mathrm{B} 0$ there are secondary peaks in apparent moistening above the melting level. There are some differences between the models, which are especially large in A0. However, there is very close agreement between SAM2D and SAM3D, providing further evidence that the 2D CRMs are suitable for this study. MOLEM and UCLA/LaRC have a weaker moistening in experiment A0 than the SAM models; both models have lower evaporation during this period and MOLEM also has a higher precipitation rate. The excess precipitation in MOLEM occurs early on the first day of the suppressed period, and this may be the result of a relatively slow spin up 

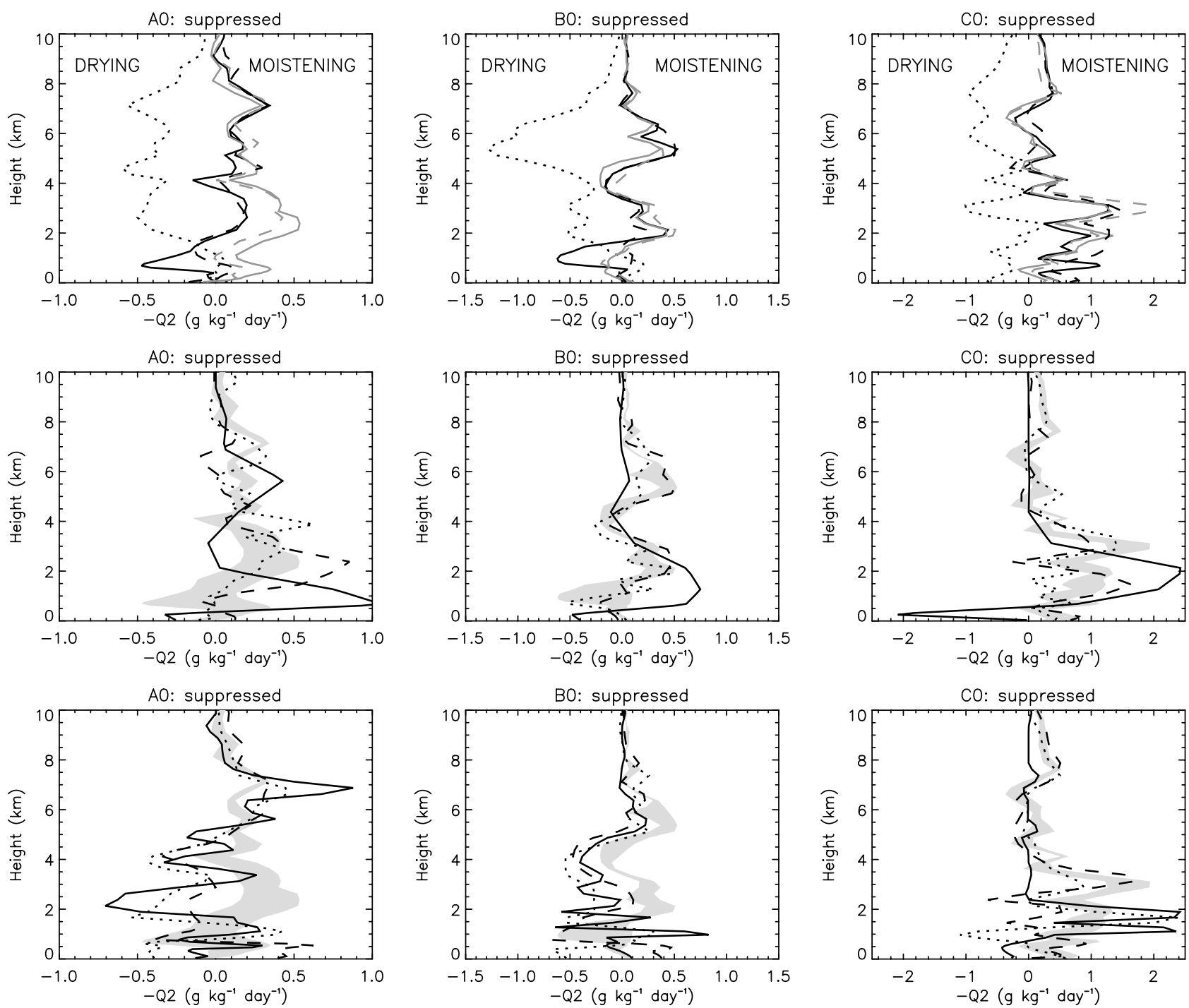

Figure 8. Simulated apparent moisture source $-\mathrm{Q}_{2}\left(\mathrm{~g} \mathrm{~kg}^{-1} \mathrm{day}^{-1}\right)$ during the suppressed period for each experiment and each model. The left-hand column shows experiment A0, the middle column experiment B0 and the right-hand column experiment $\mathrm{C} 0$. The top row shows each of the simulated $-\mathrm{Q}_{2}$ for each of the CRM integrations (MOLEM: solid black line; UCLA/LaRC: dashed black line; SAM2D: solid grey line; SAM3D: dashed grey line). The dotted line shows the large-scale moisture forcing. The middle row shows - $\mathrm{Q}_{2}$ as simulated by the WET SCMs (SCAM3: solid line; UM: dotted line; JMA dashed line). The bottom shows $-\mathrm{Q}_{2}$ as simulated by the DRY SCMs (Scripps: solid line; Meso-NH: dotted line; IFS: dashed line) The grey shading in the bottom two rows shows the range from the CRMs.

Table III. Precipitation and evaporation rates $\left(\mathrm{mm} \mathrm{day}^{-1}\right)$ and the net $(\mathrm{P}-\mathrm{E})$ during the suppressed period for each model and experiment.

\begin{tabular}{|c|c|c|c|c|c|c|c|c|c|}
\hline \multirow[b]{2}{*}{ Model } & \multirow[b]{2}{*}{$\mathrm{P}$} & \multicolumn{2}{|c|}{ A0 } & \multicolumn{4}{|c|}{ B0 } & \multicolumn{2}{|c|}{$\mathrm{C} 0$} \\
\hline & & $\mathrm{E}$ & $\mathrm{P}-\mathrm{E}$ & $\mathrm{P}$ & $\mathrm{E}$ & $\mathrm{P}-\mathrm{E}$ & $\mathrm{P}$ & E & $\mathrm{P}-\mathrm{E}$ \\
\hline SAM & 1.77 & 3.39 & -1.61 & 2.32 & 2.87 & -0.55 & 1.22 & 3.72 & -2.50 \\
\hline SAM3D & 1.94 & 3.36 & -1.42 & 2.02 & 2.96 & -0.94 & 1.37 & 4.66 & -3.29 \\
\hline UCLA/LaRC & 1.81 & 2.75 & -0.93 & 1.51 & 2.60 & -1.08 & 0.98 & 5.26 & -4.28 \\
\hline MOLEM & 2.18 & 2.44 & -0.25 & 1.89 & 2.20 & -0.32 & 1.29 & 3.90 & -2.61 \\
\hline SCAM3 & 0.88 & 2.48 & -1.60 & 1.05 & 2.36 & -1.31 & 0.41 & 4.19 & -3.78 \\
\hline UM & 1.79 & 2.97 & -1.18 & 2.30 & 2.61 & -0.32 & 1.24 & 3.95 & -2.71 \\
\hline JMA & 1.71 & 3.28 & -1.57 & 1.89 & 2.92 & -1.03 & 1.28 & 4.51 & -3.23 \\
\hline Scripps & 2.32 & 2.19 & 0.13 & 2.54 & 1.96 & 0.58 & 1.23 & 3.12 & -1.89 \\
\hline Meso-NH & 2.28 & 2.22 & 0.07 & 2.87 & 2.00 & 0.86 & 1.06 & 4.00 & -2.95 \\
\hline IFS & 2.50 & 2.87 & -0.37 & 3.19 & 2.51 & 0.68 & 1.99 & 4.05 & -2.06 \\
\hline
\end{tabular}



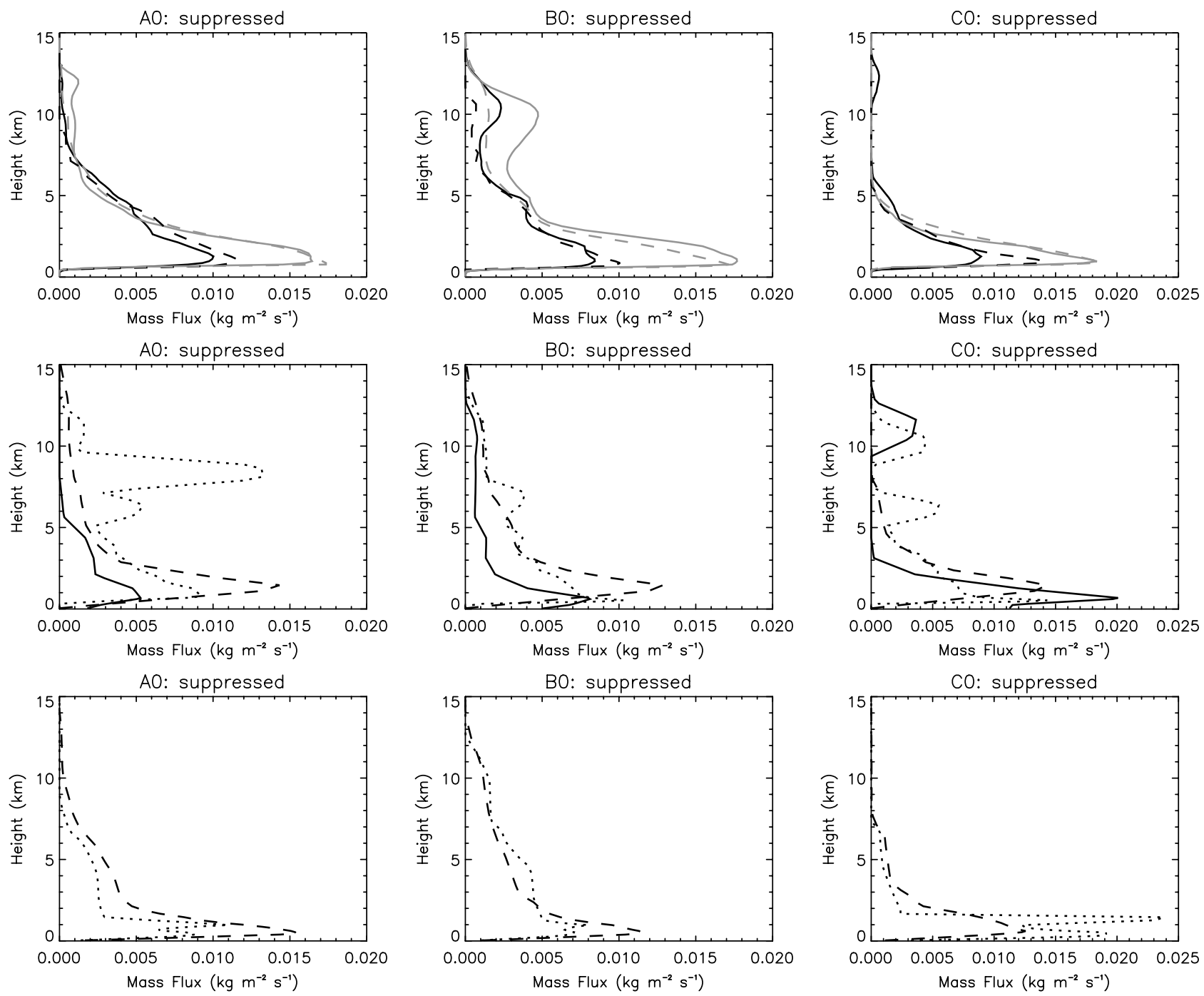

Figure 9. Simulated cloudy updraft mass flux, averaged over the suppressed period for each experiment from CRMs (top row). Similarly, simulated updraft mass flux from the WET SCMs (middle row) and the Meso-NH and IFS SCMs (bottom row), averaged over the suppressed period of each experiment. The line styles are as in Figure 8.

of the model during the first two days, when the forcing is relatively weak. The lower evaporation rates in UCLA/LaRC are related to weak surface winds that resulted from an error in the relaxation of the meridional component of the wind back to the observed values in the integrations. In MOLEM, however, the surface wind speeds and low-level humidity are in good agreement with the SAM integrations. Thus the lower evaporation rate must be attributed to the surface flux scheme. Sensitivity tests confirmed this (not shown).

The suppressed period is dominated by shallow convection. When averaged over each suppressed period, the cloudy updraft mass-flux profiles of the CRMs (shown in the top row of Figure 9) all peak at around 1-2 km and fall off rapidly with height above this level. (Here, a grid cell is deemed cloudy if its total cloud condensate-liquid and ice combined-exceeds $0.01 \mathrm{~g} \mathrm{~kg}^{-1}$.) In experiments A0 and B0, some updrafts penetrate above the melting level, around $5 \mathrm{~km}$, consistent with the moistening above this level. However, in $\mathrm{C} 0$ there are almost no updrafts penetrating above $5 \mathrm{~km}$. The SAM model was able to provide a more detailed breakdown of the cloud fields: during the suppressed period, the fraction of the cloudy columns where the cloud tops (as defined by the height at which the downward integral of cloud water path-liquid and ice-exceeds $0.01 \mathrm{~kg} \mathrm{~m}^{-2}$ ) below $4 \mathrm{~km}$ are $77 \%, 68 \%$ and $95 \%$ for experiments A0, $\mathrm{B} 0$ and $\mathrm{C} 0$ respectively in the SAM2D integrations. Whilst the general features of the mass-flux profiles are broadly consistent across the integrations, there are considerable differences in the magnitude of the mass fluxes. The higher mass fluxes in the SAM models are associated with higher cloudy updraft areas, but from the diagnostics available it is not possible to determine whether they are also associated with larger updraft velocities.

The WET SCMs are able to capture some of the moistening effects seen in the CRM integrations (Figure 8): they all show a net moistening of the column in each experiment (Table III) and the UM and JMA models both have peaks in this moistening around the $3 \mathrm{~km}$ level and a second peak above the melting level in experiments A0 and B0. Despite the ability of these models to capture some of the moistening shown in the CRMs, there is much greater variability in the vertical distribution of this effect than in the CRMs. SCAM3 generally has a lower peak in the moistening, particularly in experiment A0, and this may be associated with the much lower vertical resolution in this model. It also consistently has lower precipitation rates (by at least $0.5 \mathrm{~mm} \mathrm{day}^{-1}$ ) than all of the other models during the suppressed period of each experiment. 
Table IV. The daily mean precipitation $\left(\mathrm{mm} \mathrm{day}^{-1}\right)$ rates from each model during the active period of each experiment. The numbers in the column heading refer to the day of the integration. For each experiment the daily mean precipitation rate over the active period for each model are shown in bold.

\begin{tabular}{|c|c|c|c|c|c|c|c|c|c|c|c|c|}
\hline \multirow[b]{2}{*}{ Model } & \multicolumn{4}{|c|}{ A0 } & \multicolumn{4}{|c|}{ B0 } & \multicolumn{4}{|c|}{$\mathrm{C} 0$} \\
\hline & 11 & 12 & Mean & 8 & 9 & 10 & 11 & Mean & 6 & 7 & 8 & Mean \\
\hline SAM & 14.1 & 10.5 & 12.3 & 10.9 & 15.7 & 16.7 & 35.6 & 19.8 & 12.3 & 18.3 & 12.9 & 14.5 \\
\hline SAM3D & 12.5 & 11.4 & 12.0 & 13.3 & 15.5 & 17.5 & 36.8 & 20.8 & 14.5 & 17.6 & 13.8 & 15.3 \\
\hline UCLA/LaRC & 11.8 & 10.4 & 11.1 & 10.1 & 15.3 & 14.8 & 38.6 & 19.7 & 13.2 & 16.1 & 14.8 & 14.7 \\
\hline MOLEM & 12.7 & 10.5 & 11.6 & 13.4 & 15.1 & 16.8 & 37.4 & 20.7 & 13.3 & 17.0 & 14.0 & 14.8 \\
\hline SCAM3 & 5.7 & 9.4 & 7.6 & 9.3 & 19.8 & 10.5 & 38.9 & 19.6 & 10.0 & 13.3 & 18.8 & 14.0 \\
\hline UM & 12.1 & 10.8 & 11.5 & 12.6 & 13.6 & 18.0 & 36.6 & 20.2 & 12.2 & 16.5 & 14.8 & 14.5 \\
\hline JMA & 13.3 & 11.1 & 12.2 & 12.8 & 16.9 & 16.5 & 36.4 & 20.7 & 13.2 & 17.5 & 14.0 & 14.9 \\
\hline Scripps & 12.0 & 4.2 & 8.1 & 12.1 & 11.1 & 14.0 & 37.9 & 18.8 & 6.7 & 14.1 & 14.1 & 11.7 \\
\hline Meso-NH & 9.9 & 9.6 & 9.8 & 10.5 & 14.4 & 17.4 & 33.5 & 18.9 & 10.7 & 15.1 & 16.0 & 13.9 \\
\hline IFS & 11.4 & 10.1 & 10.8 & 10.3 & 14.0 & 16.0 & 35.5 & 19.0 & 7.2 & 16.6 & 16.2 & 13.3 \\
\hline
\end{tabular}

In experiments $\mathrm{A} 0$ and $\mathrm{B} 0$, the apparent moisture sources in the DRY SCMs differ from those in the CRMs. The DRY SCMs show a near-zero net moistening in the column, with significant drying around $2-3 \mathrm{~km}$. These models dry more strongly than the WET SCMs and CRMs during the suppressed period of A0, as seen in Figure 6. The peak lower tropospheric moistening in these models is generally below this layer. The IFS SCM, however, does produce weak moistening in the $2-3 \mathrm{~km}$ layer during the suppressed period of B0. All these models show a net drying equivalent to $0.7 \mathrm{~mm} \mathrm{day}^{-1}$ on average during $\mathrm{B} 0$, compared with a net moistening of $0.7 \mathrm{~mm} \mathrm{day}^{-1}$ in the CRMs. In experiment C0 the DRY SCMs are all able to produce a net moistening during the suppressed period, however this moistening is still weaker by about $0.8 \mathrm{~mm} \mathrm{day}^{-1}$ compared with the WET SCMs and the CRMs. In the Scripps and Meso-NH SCMs, this drying relative to the CRMs is associated with both higher precipitation rates and lower evaporation rates than the CRMs. The IFS SCM has comparable evaporation rates to the CRMs, but higher precipitation rates than the CRMs and the other SCMs.

The bottom two rows of Figure 9 show the mass-flux profiles for five of the SCMs during the suppressed period of each experiment (the mass-flux profile for the Scripps SCM is not available). A quantitative comparison between the SCMs and the CRMs or even between SCMs is not possible because the mass flux in each SCM does not necessarily describe the same quantity. However the mass-flux profiles in each of the models contain many of the characteristic features of the mass-flux profiles in the CRMs, including a peak in the mass flux at low levels, with a rapid reduction in mass flux below the melting level and weaker mass fluxes above the melting level in $\mathrm{C} 0$ than in $\mathrm{A} 0$ and $\mathrm{B} 0$. Furthermore there is no clear difference between the profiles for the WET SCMs and the DRY SCMs.

The mass-flux profiles suggest that all the SCMs are capable of simulating the shallow convective regime at these times, but that the DRY SCMs have higher precipitation production in these clouds than the WET SCMs (Table III). About half of the increase in precipitation in two of the DRY SCMs (Scripps and IFS) comes from large-scale precipitation, which accounts for approximately 10-20\% of the rainfall during the suppressed period. While the large-scale cloud fraction is not available for these models, the Scripps SCM and the Meso-NH SCM (the third DRY SCM) cloud fractions at $1-2 \mathrm{~km}$ exceed 0.5 in experiments A0, B0 and C0 (not shown). These large cloud fractions, when combined with large-scale precipitation and relative humidities of about 95\%, suggest the presence of lowlevel stratiform clouds during the suppressed period in these integrations. Although a significant fraction of the precipitation in the IFS SCM comes from the large-scale cloud scheme at this time, it does not exhibit these large low-level cloud fractions or high relative humidities.

The large low-level cloud cover in the Scripps and Meso$\mathrm{NH}$ SCMs has a significant impact on the temperature budget of these models, with strong net radiative cooling of about $12 \mathrm{~K} \mathrm{day}^{-1}$ at about $1-2 \mathrm{~km}$ above the surface. These large cooling rates are largely offset by heating from the large-scale cloud and convection schemes of the model. The large low-level cloud cover also leads to a significant reduction in the surface short-wave radiation to about half the value in the CRM simulations.

\subsection{The active period}

Table IV shows the precipitation for each model, and Figure 10 shows the simulated apparent moisture sources during the active period of each experiment. The CRMs show a generally consistent level of precipitation between the models in terms of the mean precipitation rates over the active periods, and, although there are larger variations between CRMs in the daily precipitation rates, the models generally agree over the sign of daily variations. The good agreement in precipitation rates between the CRMs is reflected in the profiles of apparent moisture sources. The variations between these profiles for the CRMs are comparable in absolute value to those during the suppressed period. However, this corresponds to a smaller fraction of the tendencies in the active than in the suppressed period.

Of the WET SCMs, both the JMA and UM SCMs show good agreement with the CRMs: their precipitation rates averaged over the active period lie within the range of the CRMs, their day-to-day precipitation variations are broadly consistent with the CRMs, and their vertical profiles of apparent moisture sources match well with those of the CRMs. SCAM3 has a much lower precipitation rate than the CRMs and the other WET SCMs in experiment A0 (about 

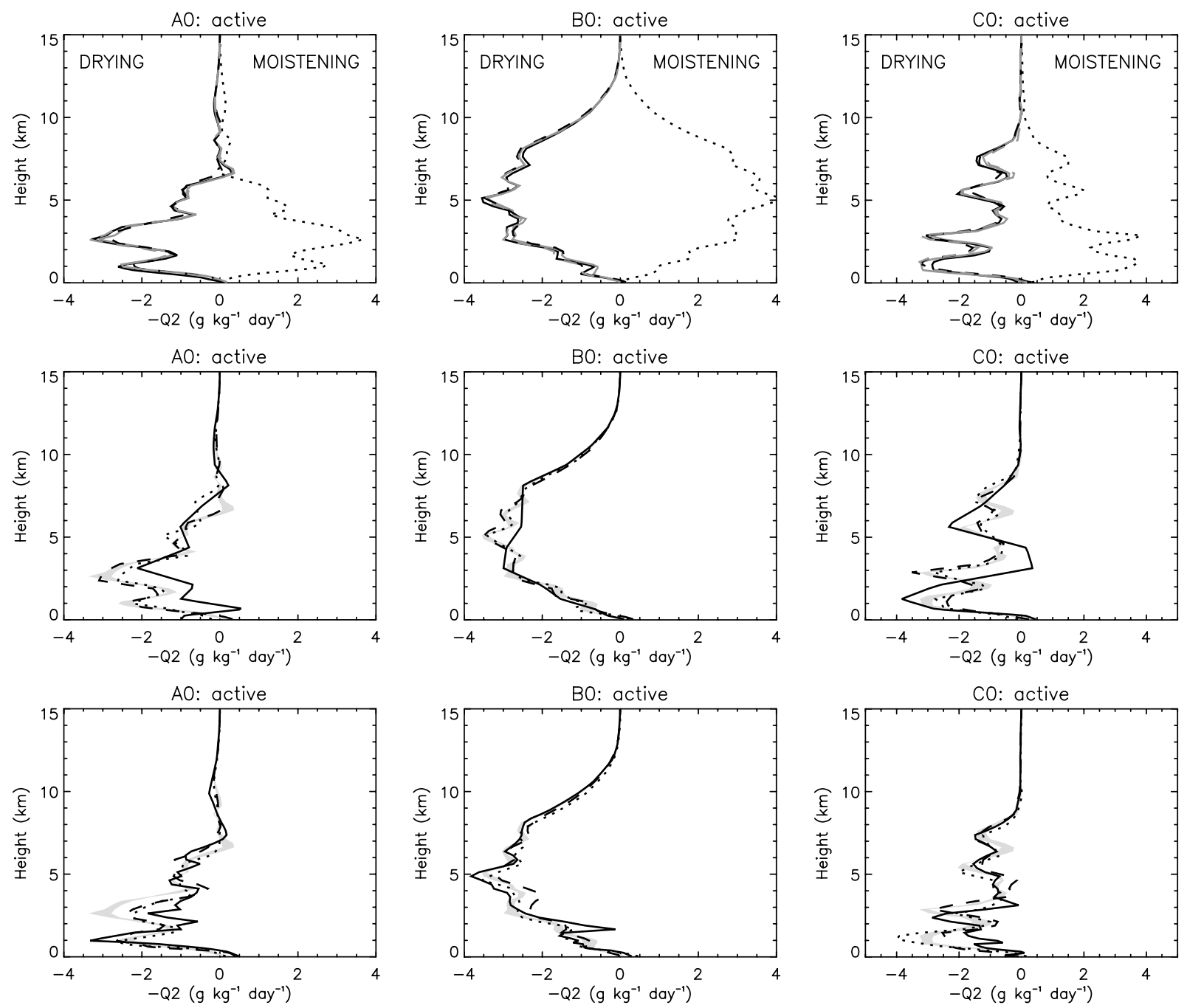

Figure 10. As for Figure 8 except for the active period of each experiment.

$4 \mathrm{~mm}$ day $^{-1}$ lower than the CRM average) and a slightly lower one during experiments $\mathrm{B} 0$ and $\mathrm{C} 0$. In addition to these lower precipitation rates, significant differences in vertical structure from the other WET SCMs can be seen in profiles of apparent moisture sources for these experiments. Although SCAM3 has a reasonable representation of the net $\mathrm{P}-\mathrm{E}$ during the suppressed period, the moistening occurs at a relatively low level in experiment A0 and the SCAM3 has much higher $\mathrm{P}-\mathrm{E}$ than the UM and JMA models during the spin-up phase of each experiment. These differences may account for some of the differences in behaviour of the SCAM3 and other WET SCMs during the active period.

The DRY SCMs have consistently lower precipitation rates than the CRMs (at least $1 \mathrm{~mm} \mathrm{day}^{-1}$ lower than the CRM average) during the active period of each experiment. These differences in mean precipitation rates are reflected in the simulated $\mathrm{Q}_{2}$ profiles of experiment $\mathrm{A} 0$, where the largest differences between the CRMs and the DRY SCMs occur around the $2-3 \mathrm{~km}$ layer where the DRY SCMs did not have convective moistening during the suppressed period. The lower precipitation rates in the DRY SCMs also lead to weaker convective heating (not shown). In addition to the variations in the magnitude of the convective heating, some significant variations in the vertical structure of convective heating arise through the coupling of the convective and radiative processes in each model.

\subsection{The transition between suppressed and active convection}

During the suppressed and active periods of each experiment, the sign of the large-scale forcing is broadly consistent throughout the free troposphere, with drying and warming during the suppressed period and moistening and cooling during the active period. This consistency breaks down during the transition between the suppressed and active periods. During the transition periods of experiments $\mathrm{A} 0$ and $\mathrm{B} 0$, the forcings are marked by periods of moistening and cooling at low levels. The depth of the cooling increases towards the end of the transition period, especially in experiment A0. The mean moisture advection during the transition period in experiments $\mathrm{A} 0$ and B0 (dotted line in top row of Figure 11) changes sign at around 5-7 km, with moistening below this level and weak drying above it. The period between the suppressed and active periods in experiment $\mathrm{C} 0$ has a different nature, in that although the large-scale forcing has cooling throughout most of the depth, it is combined with a strong drying in the lower troposphere.

Figure 11 shows the apparent moisture source in each model and experiment during the transition period. A noticeable feature of the CRMs in experiments A0 and B0 is that although the convection acts to dry the column-that is, there is more precipitation than evaporation in all the 

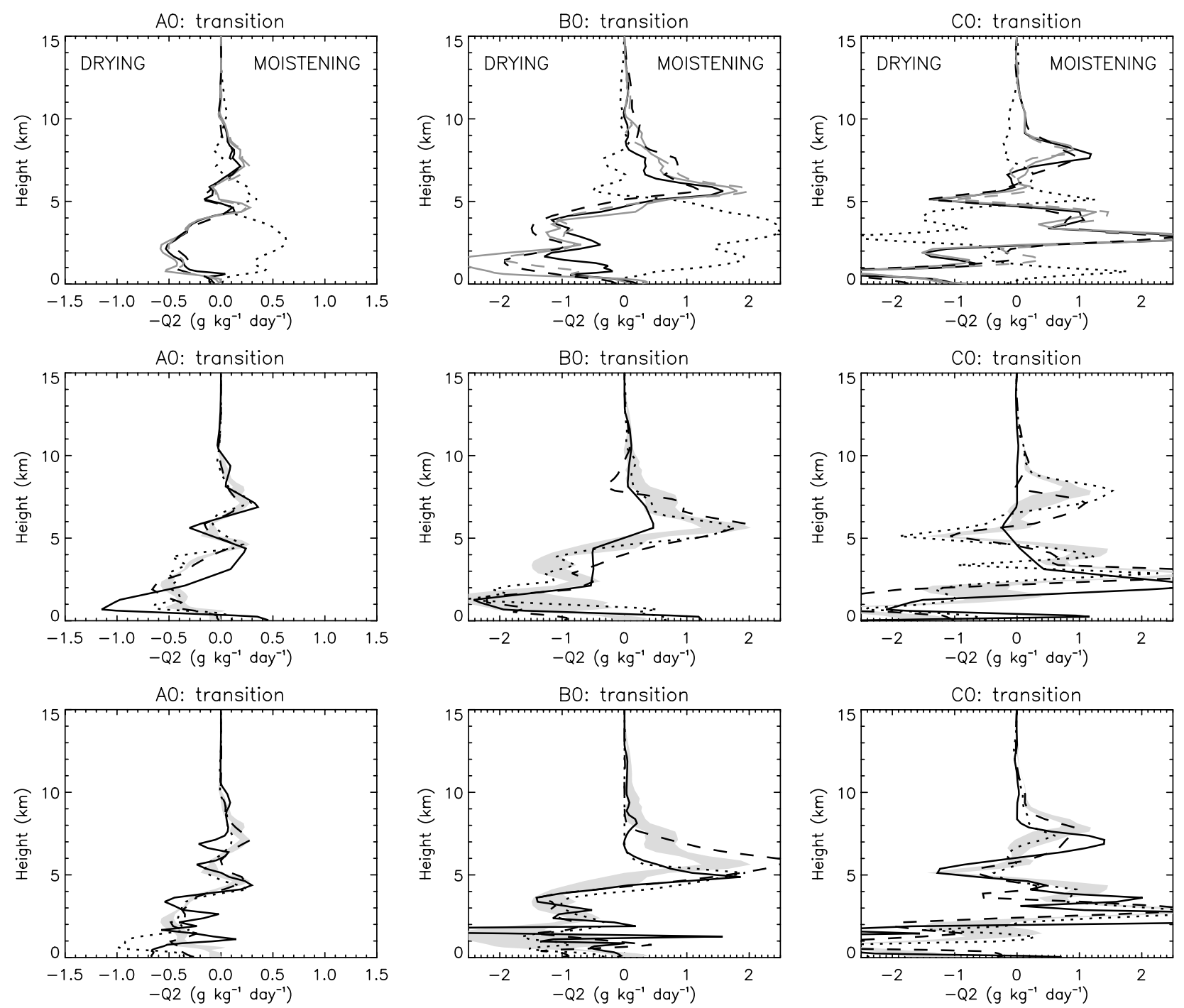

Figure 11. As for Figure 8 except for the transition period of each experiment.

models-the physical processes in the model moisten the atmosphere in the mid-tropospheric region, where there is drying by the imposed forcing. This moistening is more than enough to offset the drying by mean advection in this region. The top row of Figure 12 shows the cloudy updraft mass-flux profile for each of the CRMs. As in the suppressed period, there are some differences in the amplitude of the mass fluxes for each CRM in experiments $\mathrm{A} 0$ and B0, but the general pattern is the same for all the models, with some convection penetrating to about $12 \mathrm{~km}$ in each experiment. The mass-flux profiles show a much smaller reduction in mass flux between cloud base and the melting level than in the suppressed period, with some of the models in experiment B0 having nearly constant mass flux between 1 and $5 \mathrm{~km}$. If the five-day-long transition period of experiment A0 is broken into two pieces, the mass-flux profiles for the first two and a half days have a much stronger reduction below the melting level and are more similar to the suppressed period profiles, while those of the the second two and a half days have profiles more similar to that of the transition period in $\mathrm{B} 0$. This suggests that the initial part of the transition period in A0 features weaker and shallower convection than the latter part.

All of the SCMs are able to capture some of the essence of this moistening in experiments $\mathrm{A} 0$ and $\mathrm{B} 0$, although there are some differences in the detail. The bottom two rows of Figure 12 show the updraft mass fluxes in the SCMs (not available for the Scripps SCM). Once again, direct comparisons between the SCMs and CRMs and even between SCMs are not possible. However, it is noticeable in experiment B0 that the IFS SCM has no convective mass flux above $5 \mathrm{~km}$, and the Meso-NH SCM has very weak convection above $7 \mathrm{~km}$. These mass-flux profiles suggest that in these two models the transition to deep convection may be delayed compared with the CRMs and the WET SCMs in this experiment.

The transition period in experiment $\mathrm{C} 0$ is slightly different in nature, with a combination of cooling and drying by mean advection in different layers. The $\mathrm{Q}_{2}$ profiles for the transition period in experiment $\mathrm{C} 0$ show strong moistening below the melting level in the CRMs, the essence of which is again captured by the SCMs. The mass-flux profiles for the CRMs show no convection penetrating above $10 \mathrm{~km}$ at this time, but the convection is penetrating further than during the suppressed period in this experiment. Most of the SCMs capture this increase in depth of convection compared with that during the suppressed period.

The SAM CRM was able to provide diagnostics about the cloud fraction of shallow clouds (cloud tops $<4 \mathrm{~km}$ ), 

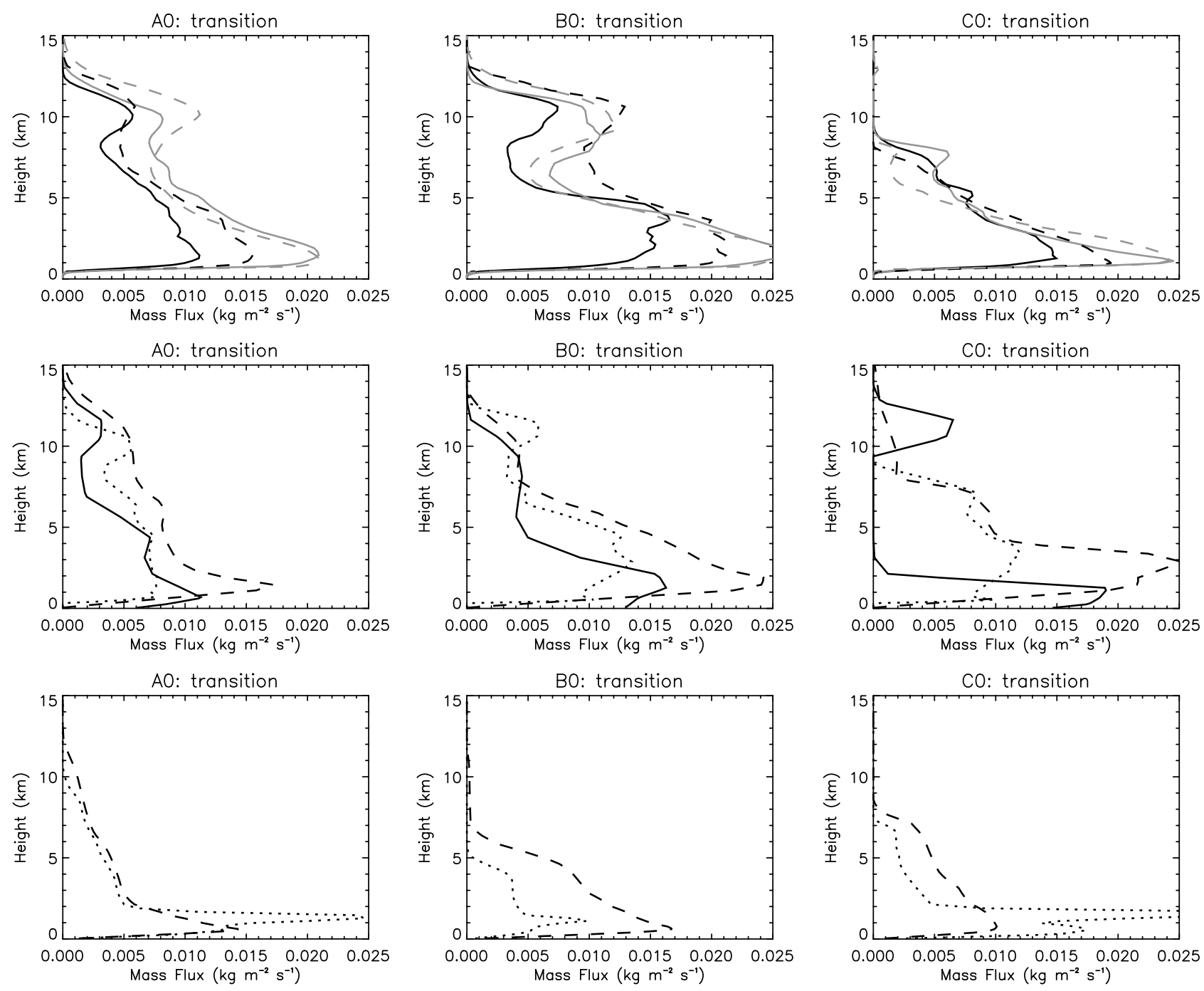

Figure 12. As for Figure 9 except for the transition period of each experiment.

mid-level clouds ( $4 \mathrm{~km}<$ cloud tops $<9 \mathrm{~km}$ ) and deep/high clouds (cloud tops $>9 \mathrm{~km}$ ), where the cloud top is defined by the height at which the top-downward integral of cloud water path (liquid and ice) exceeds $0.01 \mathrm{~kg} \mathrm{~m}^{-2}$. Figure 13 shows the total cloud fraction and precipitation rates from the SAM3D integrations, with the contribution from shallow, mid-level and deep/high clouds shown in shading. As a result of the way the cloud-top heights are defined, clouds that lie below another cloud layer (e.g. shallow clouds under a convective anvil) will not be counted. During the suppressed period, the cloud field is dominated by shallow clouds with about $10 \%$ shallow cloud fraction. During the active period, the shallow cloud fraction often remains between about 5 and $10 \%$. However, on occasions when the deep/high cloud fraction becomes very large, they may obscure the shallow clouds and so this reduction during the active period may be an artefact. These shallow clouds generally produce about $0.5 \mathrm{~mm} \mathrm{day}^{-1}$ of precipitation, but these rates can exceed $1 \mathrm{~mm}^{\text {day }^{-1}}$ in the daily mean. During the suppressed period the mid-level cloud fraction can be up to $4 \%$, but more often is around $1 \%$. Despite being less prevalent than shallow clouds, mid-level clouds precipitate at an average rate of $1 \mathrm{~mm}^{\text {day }}{ }^{-1}$ during the suppressed period. The mid-level cloud fraction increases slightly during the transition period, and tends to reach its peak during the active periods of each experiment, with cloud fractions as high as $25 \%$ at times during experiment B0. In addition, midlevel clouds can contribute up to $50 \%$ of the rainfall during the active periods. The deep/high cloud fraction increases rapidly during the transition periods and is responsible for the bulk of the cloud fraction and precipitation during the active periods.

\section{Summary and discussion}

This article has described the results from a GCSS PCCSWG Case Study to investigate periods of suppressed tropical convection and the transition from suppressed to active convection. The study makes use of results from a number of CRM and SCM integrations of three experimental periods during the suppressed phase of an MJO observed during the TOGA-COARE IOP, which were characterized by a period of suppressed convection followed by a period of active convection. In the paragraph that follows, the questions raised at the end of the introduction are addressed in compact form. In the remainder of this section, the results and their implications are discussed in more detail, along with some possible future directions.

During the suppressed periods (discussed in section 4.2), convection moistens the atmospheric column in the CRMs, with peak moistening in the lower troposphere near $3 \mathrm{~km}$. 

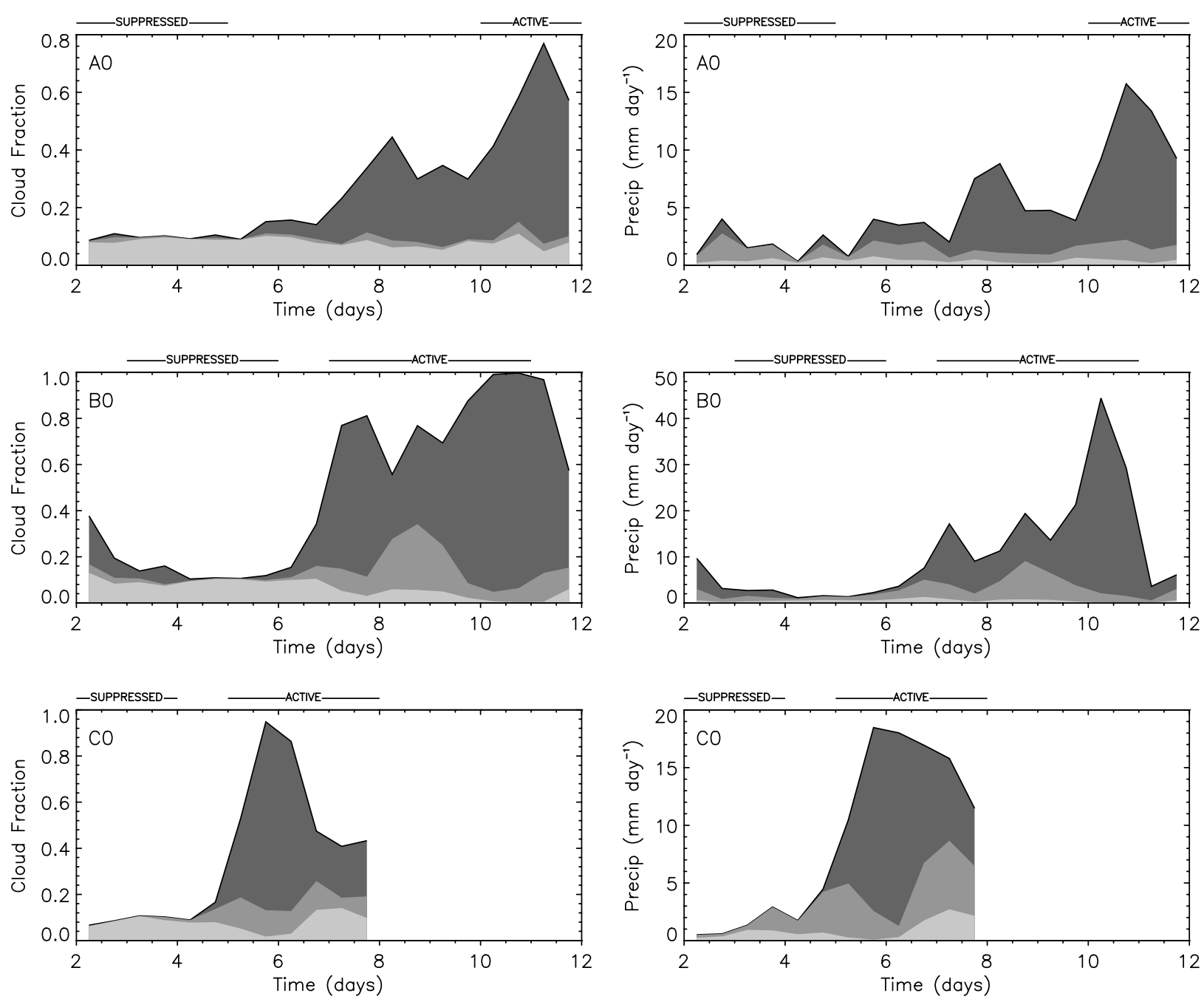

Figure 13. The left-hand column shows the total cloud fraction (solid line) in the SAM3D CRM for each integration, the shading indicates the fraction of deep/high clouds (darkest grey), mid-level clouds and shallow clouds (lightest grey). The right-hand column shows the total precipitation (solid line) and the amount from each cloud type. The data are plotted every 12 hours using averages over that period.

While the SCMs capture the structure of this moistening in most cases, convection in some (DRY) SCMs acts to dry the lower troposphere in two of the suppressed periods considered here, apparently due to strongly precipitating shallow cumulus convection (see also Figure 6). During the transition phase between the suppressed and active periods (section 4.4), convection moistens the column above the level at which it is moistened by mean advection in both the CRMs and SCMs. The depth of convection during the transition period is apparently affected in one experiment for two DRY SCMs due to the lack of moistening during the suppressed period. These effects persist into the active period of deep convection, in which the DRY SCMs tend to have both less total precipitation and weaker precipitation on the first day of the active period than the CRMs and other (WET) SCMs (Table IV).

As is common in CRM and SCM integrations with prescribed large-scale forcing, the precipitation rates are largely controlled by the forcing, and hence there is generally good agreement in the precipitation rates between the CRMs and SCMs and between different models of each type, although there is slightly more variability amongst the SCMs. Some of this variability amongst the SCMs can be attributed to the timing of precipitation events rather than differences in the total precipitation.
During the suppressed period, the CRMs show an excess of evaporation over precipitation, i.e. the column-integrated $\mathrm{Q}_{2}$ corresponds to a moistening. The moistening in the lower troposphere has a peak between 2 and $3 \mathrm{~km}$ and is associated with a predominance of shallow convection at this time, although mid-level and deep convection also occur during this suppressed period. The SCMs can be divided into two groups based mainly on their behaviour in the lower troposphere during the suppressed period in experiments A0 and B0. The WET SCMs have behaviour similar to that of the CRMs, with peak moistening in the lower troposphere at approximately $2-3 \mathrm{~km}$. The DRY CRMs fail to capture this moistening behaviour in experiments A0 and B0 and tend to show drying in the layer from $2-3 \mathrm{~km}$ and peak moistening below. This drying is associated with both lower evaporation rates and higher precipitation rates than either the WET SCMs or CRMs. Comparison of the mass-flux profiles in the SCMs suggests that all the SCMs can capture the nature of the vertical profile of convective mass flux in the CRMs. The higher precipitation rates in the DRY SCMs seem to arise from greater precipitation production within this shallow convection rather than an inability of these models to generate shallow convection at this time. The DRY SCMs are able to capture some essence of the moistening during the suppressed period of experiment $\mathrm{C} 0$, 
but on average are still drier than the WET SCMs during this period.

During the transition periods of experiments A0 and B0, the CRMs exhibit a dominance of precipitation over evaporation, i.e. the vertically integrated $\mathrm{Q}_{2}$ corresponds to drying; however, the convective processes transport moisture from regions of large-scale moistening in the lower troposphere to those associated with large-scale drying above. The SCMs are able to capture some essence of this moistening at upper levels during the transition period. The convective mass-flux profile in the CRMs during the transition periods shows some of the features of the shallow convective profiles observed during the suppressed period. Significant amounts of deep convection also occur, with a gradual transition from shallow to deep convection during the five days of the transition period in experiment A0. While the mass-flux profiles in the WET SCMs are similar to those of the CRMs, the mass-flux profiles in the DRY SCMs show less mass flux associated with deep convection in experiments $\mathrm{A} 0$ and $\mathrm{B} 0$ than the CRMs and WET SCMs, suggesting that the onset of deep convection is delayed in these models.

During the active period there is much better agreement between all the models: in fact, two of the WET SCMs (UM and JMA) show remarkable agreement with the CRMs. However, DRY SCMs have consistently lower precipitation rates than CRMs during the active period.

Time series of shallow, mid-level and deep convection show that shallow convection persists throughout the integrations; during the suppressed period the mid-level clouds produce about two-thirds of the precipitation despite accounting for around only 15\% of the cloud fraction. During the active period, the mid-level and deep/high cloud fractions increase significantly, with the mid-level clouds accounting for up to $25 \%$ of the total cloud cover and producing up to $50 \%$ of the precipitation at times.

The models all show very large temperature variations compared with those observed during all the experiments. The observed temperatures change by about $1 \mathrm{~K}$ from the initial conditions throughout each of the experimental periods. However, the model integrations show temperature changes from the initial conditions of the order of $2-3 \mathrm{~K}$ in all the models, with maximum changes of the order of $6-7 \mathrm{~K}$ in some models. Whilst some of the differences between the modelled and observed temperature changes can be attributed to errors in the large-scale forcing fields used, the large temperature variations in the model highlight a weakness in the experimental set-up used here (and in many other CRM and SCM experiments). The approach of specifying a large-scale forcing for models allows the models to develop temperature anomalies due to imbalances between the prescribed forcing and the heating due to convective and cloud processes in the model. Such anomalies would be removed in the tropical atmosphere through the feedback between the local heating and the large-scale circulation. The absence of this feedback between largescale circulation and convective heating in the present work prevents an assessment of the full effect of variations in the representation of the suppressed period on the subsequent evolution of the convection. The effect of this feedback is considered in Willett et al. (2008), who consider the behaviour of both SCMs and their parent GCMs over these same periods. The weak temperature gradient hypothesis (Sobel and Bretherton, 2000; Raymond, 2007) provides a means through which the large-scale forcing may be coupled to the local heating and provide this feedback in a singlecolumn framework. The coupling of a CRM to a large-scale linear gravity wave by Kuang (2008) is one example of the way in which this coupling can be represented and is currently being considered for use in a future GCSS PCCSWG intercomparison study.

The results of the CRM experiments presented here have shown that shallow and mid-level convection act to moisten the lower troposphere during periods of suppressed convection, as in Johnson and Lin (1997). During the transition to deep convection, convection moistens the atmosphere above the level at which the large-scale circulation deposits moisture, and this process is associated with a gradual increase in the amount of deep convection. Those SCMs that are unable to capture this moistening during the suppressed period (and hence dry out) tend to show a delay in this increase in the deep convection and have lower precipitation rates during the active period, which could be related to the formation of a low-level temperature inversion during the suppressed period in some cases. Recent refinements of entrainment rate formulations in convective parametrizations (Martin et al., 2006; Bechtold et al., 2008; Boyle et al. 2008) are highly relevant to the issues raised in the present study. It would be helpful for these models (UM, IFS and SCAM3) to repeat the simulations with updated versions of SCMs.

\section{Acknowledgements}

The authors thank the leaders of GEWEX and GCSS for their support of this effort and, in particular, the current GCSS chair Pier Siebesma and the past chair Christian Jakob. In addition, the authors would like to thank the organizers of the SPARC-GEWEX/GCSS-IGAC Invitational Workshop on the Modelling of Deep Convection and of Chemistry and their Roles in the Tropical Tropopause Layer, at which the early results of this work were discussed. The authors also thank Chris Bretherton, Dave Raymond and an anonymous referee for their constructive comments.

SJW was supported by NERC's National Centre for Atmospheric Science, Grant reference R8/H12/38/001. PNB was supported by grant NA06OAR4310055 from NOAA's CPPA program and thanks Marat Khairoutdinov for making SAM available to him. KMX and YL were supported by NASA Modeling, Analysis and Prediction Program managed by Dr Don Anderson. SFI was supported by NOAA grant NA17RJ1231.

\section{References}

Arakawa A, Schubert WH. 1974. Interaction of a cumulus ensemble with the large-scale environment. Part I. J. Atmos. Sci. 31: 674-701.

Bechtold P, Redelsperger J-L, Beau I, Blackburn M, Brinkhop S, Grandpeix J-Y, Grant A, Gregory D, Guichard F, Hoff C, Ioannidou E. 2000. A GCSS model intercomparison for a tropical squall line observed during TOGA-COARE. Part II: Intercomparison of singlecolumn models and a cloud-resolving model. Q. J. R. Meteorol. Soc. 126: 865-888.

Bechtold P, Bazile E, Guichard F, Mascart P, Richard E. 2001. A mass flux convection scheme for regional and global models. Q. J. R. Meteorol. Soc. 127: 869-886.

Bechtold P, Chaboureau J-P, Beljaars A, Betts AK, Köhler M, Miller M, Redelsperger J-L. 2004. The simulation of the diurnal cycle of convective precipitation over land in global models. Q. J. R. Meteorol. Soc. 130: 3119-3137.

Bechtold P, Koehler M, Jung T, Doblas-Reyes F, Leutbecher M, Rodwell MJ, Vitart F, Balsamo G. 2008. Advances in simulating 
atmospheric variability with the ECMWF model. From synoptic to decadal time-scales. Q. J. R. Meteorol. Soc. 134: 1337-1351.

Boville BA, Bretherton CS. 2003. Heating and dissipation in the NCAR community atmosphere model. J. Climate 16: 3877-3887.

Boyle J, Klein S, Zhang G, Xie S, Wei X. 2008. Climate model forecast experiments for TOGA COARE. Mon. Weather Rev. 136: 808-832.

Briegleb BP. 1992. Delta-Eddington approximation for solar radiation in the NCAR Community Climate Model. J. Geophys. Res. 97: 7603-7612.

Brown PRA, Heymsfield AJ. 2001. The microphysical properties of tropical convective anvil cirrus: A comparison of model and observations. Q. J. R. Meteorol. Soc. 127: 1535-1550.

Businger JA, Wyngaard JC, Izumi Y, Bradley EF. 1971. Flux-profile relationships in the atmospheric surface layer. J. Atmos. Sci. 28: $181-189$.

Brown AR, Derbyshire SH, Mason PJ. 1994. Large-eddy simulation of stable atmospheric boundary layers with a revised stochastic subgrid model. Q. J. R. Meteorol. Soc. 120: 1485-1512.

Chaboureau J-P, Pinty J-P. 2006. Validation of a cirrus parameterization with Meteosat Second Generation. Geophys. Res. Lett. 33: L03815. DOI:10.1029/2005GL024725.

Ciesielski PE, Johnson RH, Haertel PT, Wang J. 2003. Corrected TOGA COARE sounding humidity data: Impact on diagnosed properties of convection and climate over the warm pool. J. Climate 16: 2370-2384.

Collins WD, Rasch PJ, Boville BA, Hack JJ, McCaa JR, Williamson DL, Kiehl JT, Briegleb B, Bitz C, Lin S-J, Zhang M, Dai Y. 2006. The Community Climate System Model Version 3 (CCSM3). J. Climate 19: $2122-2143$.

Cuxart J, Bougeault Ph, Redelsperger JL. 2000. A turbulence scheme allowing for mesoscale and large-eddy simulations. Q. J. R. Meteorol. Soc. 126: $1-30$.

Derbyshire SH, Beau I, Bechtold P, Grandpeix J-Y, Piriou J-M, Redelsperger J-L, Soares PMMM. 2004. Sensitivity of moist convection to environmental humidity. Q. J. R. Meteorol. Soc. 130: 3055-3079.

Donner LJ, Seman CJ, Hemler RS. 1999. Three-dimensional cloudsystem modeling of GATE convection. J. Atmos. Sci. 56: 1885-1912.

ECMWF. 2008. IFS documentation. Available from http://www. ecmwf.int/research/ifsdocs/.

Edwards JM, Slingo A. 1996. Studies with a flexible new radiation code. Part I. Choosing a configuration for a large-scale model. Q. J. R. Meteorol. Soc. 122: 689-719.

Emanuel KA, Živković-Rothman M. 1999. A convection scheme for use in climate models. Part I: Development and evaluation. J. Atmos. Sci. 56: $1766-1782$

Emanuel KA, Neelin JD, Bretherton CS. 1994. On large-scale circulations in convecting atmospheres. Q. J. R. Meteorol. Soc. 120: 1111-1143.

Fu Q. 1996. An accurate parameterization of the solar radiative properties of cirrus clouds for climate models. J. Climate 9: 2058-2082.

Fu Q, Liou KN. 1993. Parameterization of radiative properties of clouds. J. Atmos. Sci. 50: 2008-2025.

Fu Q, Yang P, Sun WB. 1998. An accurate parameterization of the infrared radiative properties of cirrus clouds for climate models. J. Climate 11: 2223-2237.

Ghan S et al. 2000. A comparison of single column model simulations of summertime midlatitude continental convection. J. Geophys. Res. 105(D2): 2091-2124.

Grabowski WW. 2003. MJO-like coherent structures: Sensitivity simulations using the cloud-resolving convection parameterization (CRCP). J. Atmos. Sci. 60: 847-864.

Grabowski W, Wu X, Moncrieff MW. 1996. Cloud-resolving modeling of tropical cloud systems during Phase III of the GATE. Part I: Two-dimensional experiments. J. Atmos. Sci. 53: 3684-3709.

Grabowski WW, Wu X, Moncrieff MW, Hall WD. 1998. Cloud-resolving modeling of cloud systems during Phase III of GATE. Part II: Effects of resolution and the third spatial dimension. J. Atmos. Sci. 55: 3264-3282.

Grabowski WW, Bechtold P, Cheng A, Forbes R, Halliwell C, Khairoutdinov M, Lang S, Nasuno T, Petch J, Tao W-K, Wong R, Wu X, Xu K-M. 2006. Daytime convective development over land: a model intercomparison based on LBA observations. Q. J. R. Meteorol. Soc. 132: 317-344.

Gregory D, Rowntree PR. 1990. A mass flux convection scheme with representation of cloud ensemble characteristics and stabilitydependent closure. Mon. Weather Rev. 118: 1483-1506.

Guichard F, Petch JC, Redelsperger J-L, Bechtold P, Chaboureau J-P, Cheinet S, Grenier H, Grabowski W, Jones CJ, Köhler M, Piriou J-M, Tailleux R, Tomasini M. 2004. Modeling the diurnal cycle of deep precipitating convection over land with cloud-resolving models and single-column models. Q. J. R. Meteorol. Soc. 130: 3139-3172.

Hack JJ. 1994. Parameterization of moist convection in the NCAR Community Climate Model (CCM2). J. Geophys. Res. 99: 5551-5568.
Heymsfield AJ. 2003. Properties of tropical and midlatitude ice cloud particle ensembles. Part II: Applications for mesoscale and climate models. J. Atmos. Sci. 60: 2592-2611.

Holtslag AAM, Boville BA. 1993. Local versus nonlocal boundary-layer diffusion in a global climate model. J. Climate 6: 1825-1842.

Iacobellis SF, Somerville RCJ. 2000. Implications of microphysics for cloud-radiation parametrizations: Lessons from TOGA-COARE. J. Atmos. Sci. 57: 161-183.

Iacobellis SF, McFarquahr GM, Mitchell DL, Somerville RCJ. 2003. The sensitivity of radiative fluxes to parametrized cloud microphysics. J. Climate 16: 2979-2996.

Japan Meteorological Agency. 2006. 'Outline of the Operational Forecast and Analysis System of the Japan Meteorological Agency (March 2006)'. Available from http://www.jma.go.jp/jma/jmaeng/jma-center/nwp/nwp-top.htm.

Johnson RH, Lin X. 1997. Episodic trade-wind regimes over the Western Pacific warm pool. J. Atmos. Sci. 54: 2020-2034.

Johnson RH, Rickenbach TM, Rutledge SA, Ciesielski PE, Schubert WH. 1999. Trimodal characteristics of tropical convection. J. Climate 12: 2387-2418.

Khairoutdinov MF, Randall DA. 2003. Cloud-resolving modeling of the ARM summer 1997 IOP: Model formulation, results, uncertainties and sensitivities. J. Atmos. Sci. 60: 607-625.

Khairoutdinov MF, Randall DA, DeMott CA. 2008. Evaluation of the simulated interannual and subseasonal variability in an AMIP-style simulation using the CSU multi-scale modeling framework. J. Climate 21: 413-431

Krueger SK. 1988. Numerical simulation of tropical cumulus clouds and their interaction with the subcloud layer. J. Atmos. Sci. 45: 2221-2250.

Krueger SK, Fu Q, Liou KN, Chin H-NS. 1995. Improvements of an icephase microphysics parameterization for use in numerical simulations of tropical convection. J. Appl. Meteorol. 34: 281-287.

Kuang Z. 2008. Modeling the interaction between cumulus convection and linear gravity waves using a limited-domain cloud systemresolving model. J. Atmos. Sci. 65: 576-591.

Lafore J-P, Stein J, Asencio N, Bougeault P, Ducrocq V, Duron J, Fischer C, Héreil P, Mascart P, Masson C, Pinty J-P, Redelsperger J-L, Richard E, Vilà-Guerau de Arellano J. 1998. The Meso-NH Atmospheric Simulation System. Part I: adiabatic formulation and control simulations. Scientific objectives and experimental design. Ann. Geophys. 16: 90-109.

Lin X, Johnson RH. 1996. Heating, moistening and rainfall over the Western Pacific Warm Pool during TOGA-COARE. J. Atmos. Sci. 53: 3367-3383.

Lin Y-L, Farley RD, Orville HD. 1983. Bulk parameterization of the snow field in a cloud model. J. Clim. Appl. Meteorol. 22: 1065-1092.

Lin J-Y et al. 2006. Tropical intraseasonal variability in 14 ICPP AR4 climate models. Part I: Convective signals. J. Climate 19: 2665-2690.

Lock AP, Brown AR, Bush MR, Martin GM, Smith RNB. 2000. A new boundary layer mixing scheme. Part I: Scheme description and SCM tests. Mon. Weather Rev. 128: 3187-3199.

Lord SJ, Willoughby HE, Piotrowicz JM. 1984. Role of a parameterized ice-phase microphysics in an axisymmetric, nonhydrostatic tropical cyclone model. J. Atmos. Sci. 41: 2836-2848.

Madden RA, Julian PR. 1972. Description of global-scale circulation cells in the Tropics with a 40-50 day period. J. Atmos. Sci. 29: 1109-1123.

Mann HB, Whitney DR. 1947. On a test of whether one of two random variables is stochastically larger than the other. Ann. Math. Stat. 18: 50-60.

Mapes BE, Zuidema P. 1996. Radiative-dynamical consequences of dry tongues in the tropical troposphere. J. Atmos. Sci. 53: 620-638.

Mapes BE, Ciesielski PE, Johnson RL. 2003. Sampling errors in rawinsonde array budgets. J. Climate 60: 2697-2714.

Martin GM, Ring MA, Pope VD, Jones A, Dearden C, Hinton TJ. 2006. The physical properties of the atmosphere in the new Hadley Centre Global Environment Model (HadGEM1). Part I: model description and global climatology. J. Climate 19: 1274-1301.

Masunaga H, Satoh M, Miura H. 2008. A joint satellite and global cloudresolving model analysis of a Madden-Julian oscillation event: Model diagnosis. J. Geophys. Res. 113: D17210. DOI:10.1029/2008JD009986.

Mellor GL, Yamamda T. 1974. A hierarchy of turbulence closure models for planetary boundary layers. J. Atmos. Sci. 31: 1791-1806.

Mlawer EJ, Taubman SJ, Brown PD, Iacono MJ, Clough SA. 1997. Radiative transfer for inhomogeneous atmospheres: RRTM, a validated correlated-k model for the longwave. J. Geophys. Res. 102: $16663-16682$

Morcrette J-J. 2002. Assessment of the ECMWF model cloudiness and surface radiation fields at the ARM-SGP site. Mon. Weather Rev. 130 $257-277$. 
Petch JC, Gray MEB. 2001. Sensitivity studies using a cloud resolving model simulation of the tropical West Pacific. Q. J. R. Meteorol. Soc. 127: 2287-2306.

Petch JC, Willett M, Wong RY, Woolnough SJ. 2007. Modelling suppressed and active convection. Comparing a numerical weather prediction, cloud resolving and single column model. Q. J. R. Meteorol. Soc. 133: 1087-1100.

Petch JC, Blossey PN, Bretherton CS. 2008. Differences in the lower troposphere in two- and three-dimensional cloud-resolving model simulations of deep convection. Q. J. R. Meteorol. Soc. 134: 1941-1946.

Pinty J-P, Jabouille P. 1998. 'A mixed-phase cloud parameterization for use in mesoscale non-hydrostatic model: simulations of a squall line and of orographic precipitation'. In Proceedings of the AMS conference on cloud physics, 17-21 August 1998, Everett, WA; pp 217-220.

Randall DA, Khairoutdinov MF, Arakawa A, Grabowski WW. 2003. Breaking the cloud parameterization deadlock. Bull. Am. Meteorol. Soc. 84: 1547-1564.

Rasch PJ, Kristjansson JE. 1998. A comparison of the CCM3 model climate using diagnosed and predicted condensate parameterizations. J. Climate 11: 1587-1614.

Raymond DJ. 2007. Testing a cumulus parametrization with a cumulus ensemble model in weak-temperature-gradient mode. Q. J. R. Meteorol. Soc. 133: 1073-1085.

Redelsperger J-L, Brown P, Guichard F, Hoff C, Kawasima M, Lang S, Montemerle TH, Nakamura K, Saito K, Seman C, Tao W-K, and Donner LJ. 2000. A GCSS model intercomparison for a tropical squal line observed during TOGA-COARE. Part I: Cloud-resolving models Q. J. R. Meteorol. Soc. 126: 823-864.

Ringer MA, Martin GM, Greeves CZ, Hinton TJ, James PM, Pope VD, Scaife AA, Stratton RA, Inness PM, Slingo JM, Yang G-Y. 2006. The physical properties of the atmosphere in the new Hadley Centre Global Environment Model (HadGEM1). Part II: Aspects of variability and regional climate. J. Climate 19: 1302-1326.

Shutts GJ, Gray MEB. 1994. A numerical modeling study of the geostrophic adjustment process following deep convection. Q. J. R. Meteorol. Soc. 120: 1145-1178.

Smith RNB. 1990. A scheme for predicting layer clouds and their water content in a general circulation model. Q. J. R. Meteorol. Soc. 116: $435-460$.
Sobel AH, Bretherton CS. 2000. Modeling tropical precipitation in a single column. J. Climate 13: 4378-4392.

Swann H. 1998. Sensitivity to the representation of precipitating ice in CRM simulations of deep convection. Atmos. Res. 47-48: 415-435.

Tiedtke M. 1993. Representation of clouds in large-scale models. Mon. Weather Rev. 121: 3040-3061.

Webster PJ, Lukas R. 1992. TOGA COARE: The Coupled Ocean-Atmosphere Response Experiment. Bull. Am. Meteorol. Soc. 73: $1377-1416$

Wheeler M, Kiladis GN. 1999. Convectively coupled equatorial waves: Analysis of clouds and temperature in the wavenumber-frequency domain. J. Atmos. Sci. 56: 374-399.

Willett MR, Bechtold P, Williamson DL, Petch JC, Milton SF, Woolnough SJ. 2008. Modeling suppressed and active convection: Comparisons between three global atmospheric models. Q. J. R. Meteorol. Soc. 134: 1881-1896.

Wu X, Moncrieff MW, Emanuel KA. 2000. Evaluation of the large-scale forcing data during TOGA COARE for cloud-resolving models and single-column models. J. Atmos. Sci. 57: 2977-2985.

Xie S-C et al. 2002. Intercomparison and evaluation of cumulus parameterizations under summertime midlatitude continental conditions. Q. J. R. Meteorol. Soc. 128: 1095-1135.

Xu K-M, Krueger SK. 1991. Evaluation of cloudiness parametrizations using a cumulus ensemble model. Mon. Weather Rev. 119: 342-367.

Xu K-M, Randall DA. 1996. Explicit simulation of cumulus ensembles with the GATE Phase III data: Comparison with observations. J. Atmos. Sci. 53: 3710-3736.

$\mathrm{Xu} \mathrm{K-M}$ et al. 2002. An intercomparison of cloud-resolving models with the ARM summer 1997 IOP data. Q. J. Roy. Meteorol. Soc. 128: 593-624.

Yanai M, Esbensen S, Chu JH. 1973. Determination of bulk properties of tropical cloud clusters from large-scale heat and moisture budgets. J. Atmos. Sci. 30: 611-627.

Zhang GJ, McFarlane NA. 1995. Sensitivity of climate simulations to the parameterization of cumulus convection in the Canadian Climate Center general circulation model. Atmos. - Ocean 33: 407-446.

Zhang GJ, Mu M. 2005. Simulation of the Madden-Julian oscillation in the NCAR CCM3 using a revised Zhang-McFarlane convection parameterization scheme. J. Climate 19: 4046-4064. 